\title{
Inhibition of the sodium-glucose co-transporter 2 in the elderly: clinical and mechanistic insights into safety and efficacy
}

\author{
(iD) Riobaldo Cintra ${ }^{1}$ \\ (iD) Filipe A Moura ${ }^{1}$ \\ Luis Sergio F de Carvalho ${ }^{\mathbf{1}, 2}$ \\ (iD) Joaquim Barreto ${ }^{1}$ \\ (iD) Marcos Tambascia ${ }^{3}$ \\ (iD) Roberto Pecoits-Filho ${ }^{4}$ \\ (iD) Andrei C. Sposito ${ }^{1,2}$
}

1. Laboratory of Atherosclerosis and Vascular Biology, Unicamp, Campinas, SP, Brasil 2. Cardiology Division, State University of Campinas (Unicamp), Campinas, SP, Brasil 3. Endocrinology Division, State University of Campinas (Unicamp), Campinas, SP, Brasil 4. Pontifícia Universidade Católica do Paraná, Curitiba, PR, Brasil

\section{SUMMARY}

The prevalence of type 2 diabetes mellitus (T2DM) in the elderly grew sharply over the last decade. Reduced insulin sensitivity and secretory capacity, weight gain, sarcopenia, and elevated adiposity are all common metabolic and body changes in the aging population that favor an increased risk of hypoglycemia, frailty syndrome, falls, and cognitive dysfunction. First line antidiabetic therapy is frequently not safe in older individuals because of its high risk of hypoglycemia and prevalent co-morbid diseases, such as chronic kidney disease, osteoporosis, cardiovascular disease, and obesity. Sodium-glucose cotransporter 2 inhibitor (SGLT2i) is a new class of antidiabetic therapy that inhibits glucose and sodium reabsorption on renal proximal convoluted tubule. Its effect is well demonstrated in various clinical scenarios in the younger population. This review and metanalysis describe particularities of the SGLT2i on the elderly, with mechanistic insights of the potential benefit and remaining challenges about the use of these drugs in this important age group. Further, we will present a meta-analysis of the main effects of SGLT2i reported in post-hoc studies in which the median age of the subgroups analyzed was over 60 years. Despite the absence of specific clinical trials for this population, our findings suggest that SGLT2i therapy on older individuals is effective to lower glucose and maintain its effect on systolic blood pressure and body weight.

KEYWORDS: Sodium-glucose transporter/antagonists \& inhibitors. Diabetes mellitus. Aging. Effectiveness.

\section{INTRODUCTION}

The rapid increase in longevity and the prevalence of type 2 diabetes mellitus (T2DM) are among the most striking epidemiological challenges of recent decades. As a consequence, nearly $50 \%$ of individuals with T2DM are 65 years old or older ${ }^{1}$, and $27 \%$ of those aged 65 years or older have T2DM². These figures represent an increase of $62 \%$ over the last decade ${ }^{3}$.
Over the last 25 years, population aging was the main factor for the $41 \%$ global increase in deaths due to cardiovascular disease ${ }^{4}$. For these older individuals, the presence of T2DM has doubled the risk of death ${ }^{5}$. Since these evolving changes are of particular importance, special attention must be paid to clinical and mechanistic features related to aging as well as 
to the interaction of these biological changes with hypoglycemic therapies.

Aging predisposes a person to T2DM in a number of mechanisms, which include apoptosis of beta cells, reduced insulin sensitivity from sarcopenia, decreased mitochondrial activity, and increased lipid content in cell membranes - particularly in hepatocyte and myocyte ${ }^{6,7}$. Beta cells of aged individuals have reduced secretory capacity. This is probably due to different mechanisms such as reduced glucose sense transporters, reduced insulin secretion related to mitochondrial activity, and impaired function of K-ATP voltage channels ${ }^{8}$. In clinical studies, this phenomenon has been related to reductions in the amplitude of insulin pulse secretion and glucose-stimulated insulin secretion ${ }^{8,9}$. Aging also leads to a progressive decline in insulin sensitivity, which is the result of processes that include increased adiposity, sarcopenia, and mitochondrial dysfunction 6,7,10,11. A successful glucose-lowering strategy for the elderly must account for the limitations in increasing insulin secretion and the reduced effect of insulin on muscular and adipose tissues. In line with these assumptions, lowering the threshold for glycosuria has emerged as a promising therapeutic target for T2DM elderlies.

About $90 \%$ of glucose filtered by the kidney is reabsorbed by the sodium glucose co-transporter 2 (SGLT2), which is the most active co-transporter expressed at the proximal convoluted tubule ${ }^{12}$. In healthy individuals, virtually all filtered glucose above $180 \mathrm{mg} / \mathrm{dL}$ is excreted; however, in diabetic individuals, glucose threshold excretion is at least $20 \%$ higher, probably due to up-regulation of SGLT2 and glucose transport channels in the nephron ${ }^{13}$.

From an evolutionary perspective, it seems reasonable that an efficient mechanism to preserve energy loss through urine has been selected ${ }^{13}$. On the other hand, higher glycemic levels may contribute to metabolic disturbances, such as insulin resistance and reduced insulin secretion. Therefore, an adequate balance between retaining and losing glucose through the kidney is of particular interest and certainly plays a role in helping the maintenance of a favorable metabolic profile. Accordingly, SGLT2 inhibitors (SGLT2i) reduce glycemia in an insulin-independent manner and contribute to the improvement of beta cells function ${ }^{14,15}$ and insulin sensitivity ${ }^{14-17}$.

Only recently, clinical trials with SGLT2i started enrolling older individuals, and many questions remain open to debate. To tackle this issue, this review presents a meta-analysis of the main effects of SGLT2i reported in post-hoc studies focused on elderly individuals (Table 1 and Table 2) and describes particularities of the SGLT2i effect on the elderly, with mechanistic insights of the potential benefits and remaining challenges about the use of these drugs in this important age group.

Methods for Systematic Review and Meta-analysis of SGLT2i Trials in Elderly

We used the methods recommended by the Cochrane guidelines to conduct the meta-analysis and reported our findings according to the PRISMA (Preferred Reporting Items for Systematic reviews and Meta-Analyses) statement ${ }^{29}$. All procedures performed for this analysis are presented in detail in the supplement.

\section{Role of the funding source}

There was no funding source for this study. The corresponding authors had full access to all the data in the study and were fully responsible for the decision to submit it for publication.

\section{EFFICACY IN CLINICAL TRIALS}

\section{Anti-hyperglycemic effects}

Recent guidelines have defined glycemic therapeutic goals that are less stringent in older individuals when compared to younger ones, based on the increased risk of hypoglycemia. Customized therapeutic targets consider functional status, comorbidities, and life expectancy ${ }^{30}$. More leniency with higher glucose levels, however, does not necessarily prevent hypoglycemia ${ }^{31}$, but it could instead favor dehydration, cognitive decline, falls, and other complications $^{30}$. Therefore, a more desirable option would be a potent antidiabetic treatment that bears a low risk for hypoglycemia. SGLT2i qualifies for this premise being associated with a risk of hypoglycemia of less than $1 \%$ in the elderly when used alone, a number three times lower than that obtained with DPP-IV inhibitors and 15 to 20 times lower than the one observed with sulphonylurea ${ }^{32}$.

Aging may influence the efficacy of SGLT2i by either indirect or direct mechanisms. Indirectly, the age-dependent decline in glomerular filtration rate (GFR) may reduce the glucose-lowering effect of these drugs via down-regulation of the tubular 
TABLE 1. CLINICAL CHARACTERISTICS OF PATIENTS ENROLLED IN THE META-ANALYSIS

\begin{tabular}{|c|c|c|c|c|c|c|c|c|c|}
\hline & $\mathrm{n}$ & $\begin{array}{l}\text { Fol- } \\
\text { low-up } \\
\text { time } \\
\text { (years) }\end{array}$ & whites_ & women & $\begin{array}{l}\text { Age at } \\
\text { entry } \\
\text { (years) }\end{array}$ & $\begin{array}{l}\text { CKD } \\
(\%)\end{array}$ & $\begin{array}{l}\text { CKD } \\
\text { stages } \\
\text { III or IV } \\
(\%)\end{array}$ & Treatment arms & $\begin{array}{l}\text { Publi- } \\
\text { cation } \\
\text { year }\end{array}$ \\
\hline Zinman et al. ${ }^{18}, 2015$ & 7020 & 3.1 & 72.3 & 29 & 63.2 & 26 & 26 & $\begin{array}{l}\text { Placebo vs } \\
\text { Empagliflozin 10/25mg }\end{array}$ & 2015 \\
\hline Tikkanen et al. ${ }^{\mathbf{1 9}}, 2015$ & 549 & 0.23 & 93.7 & 39.9 & 60.2 & 0 & 0 & $\begin{array}{l}\text { Placebo vs } \\
\text { Empagliflozin 10mg }\end{array}$ & 2015 \\
\hline $\begin{array}{l}\text { Barnett et al. }{ }^{20}, 2014 \\
(C K D \text { II) }\end{array}$ & 290 & 1 & 68.3 & 39 & 62.6 & 100 & 0 & $\begin{array}{l}\text { Placebo vs } \\
\text { Empagliflozin 10/25mg }\end{array}$ & 2014 \\
\hline $\begin{array}{l}\text { Barnett et al. }{ }^{20}, 2014 \\
(\text { CKD III) }\end{array}$ & 374 & 1 & 56.1 & 43 & 64.9 & 100 & 100 & $\begin{array}{l}\text { Placebo vs } \\
\text { Empagliflozin 25mg }\end{array}$ & 2014 \\
\hline $\begin{array}{l}\text { Barnett et al. }{ }^{20}, 2014 \\
\text { (CKD IV) }\end{array}$ & 74 & 1 & 50 & 46 & 64.1 & 100 & 100 & $\begin{array}{l}\text { Placebo vs } \\
\text { Empagliflozin 25mg }\end{array}$ & 2014 \\
\hline Bolinder et al. 21, 2014 & 182 & 1.96 & 100 & 44.4 & 60.7 & 64 & 3 & $\begin{array}{l}\text { Placebo+MTF vs } \\
\text { Dapagliflozin 10mg+MTF }\end{array}$ & 2014 \\
\hline Matthaei et al. ${ }^{22}, 2015$ & 218 & 0.46 & 95 & 49 & 61 & 0 & 0 & $\begin{array}{l}\text { Placebo+MTF/SFU vs } \\
\text { Dapagliflozin 10mg+MTF/SFU }\end{array}$ & 2015 \\
\hline Kohan et al. ${ }^{23}, 2014$ & 252 & 1.96 & 86 & 35 & 67 & 100 & 96 & $\begin{array}{l}\text { Placebo vs } \\
\text { Dapagliflozin 5/10mg }\end{array}$ & 2014 \\
\hline Leiter et al. ${ }^{24}, 2014$ & 962 & 1 & 84 & 31.7 & 62.9 & 0 & 0 & $\begin{array}{l}\text { Placebo vs } \\
\text { Dapagliflozin 10mg }\end{array}$ & 2015 \\
\hline Neal et al. ${ }^{25}, 2015$ & 2072 & 1 & 75 & 34 & 62.7 & 25 & NR & $\begin{array}{l}\text { Placebo vs } \\
\text { Canaglifozin 100/300mg }\end{array}$ & 2015 \\
\hline Yale et al. ${ }^{\mathbf{2 6}}, 2014$ & 269 & 1 & 79.9 & 39.4 & 68.5 & 100 & 100 & $\begin{array}{l}\text { Placebo vs } \\
\text { Canaglifozin 300mg }\end{array}$ & 2014 \\
\hline Sinclair et al. ${ }^{27}, 2014$ & 1085 & 0.5 & 84.4 & 41 & 67 & 100 & 100 & $\begin{array}{l}\text { Placebo vs } \\
\text { Canaglifozin 100/300mg }\end{array}$ & 2014 \\
\hline Bode et al. ${ }^{28}, 2014$ & 714 & 1.96 & 77.3 & 44.5 & 64.6 & 0 & 0 & $\begin{array}{l}\text { Placebo vs } \\
\text { Canaglifozin 100/300mg }\end{array}$ & 2015 \\
\hline
\end{tabular}

TABLE 2. BASELINE LABORATORY AND CLINICAL DATA OF PATIENTS ENROLLED IN THE META-ANALYSIS

\begin{tabular}{|c|c|c|c|c|c|c|c|c|}
\hline & \multicolumn{2}{|c|}{ HbA1c in SGLT2i arm } & \multicolumn{2}{|c|}{ SBP in SGLT2i arm } & \multicolumn{2}{|c|}{ DBP in SGLT2i arm } & \multicolumn{2}{|c|}{$\begin{array}{l}\text { Body weight in SGLT2i } \\
\text { arm }\end{array}$} \\
\hline & $\begin{array}{l}\text { Baseline } \\
(\%)\end{array}$ & $\begin{array}{l}\text { Change }^{*} \\
(\%)\end{array}$ & $\begin{array}{l}\text { Baseline } \\
(\mathrm{mmHg})\end{array}$ & $\begin{array}{l}\text { Change }^{*} \\
(\mathrm{mmHg})\end{array}$ & $\begin{array}{l}\text { Baseline } \\
(\mathrm{mmHg})\end{array}$ & $\begin{array}{l}\text { Change* }^{*} \\
(\mathrm{mmHg})\end{array}$ & $\begin{array}{l}\text { Baseline } \\
(\mathrm{Kg})\end{array}$ & $\begin{array}{l}\text { Change* } \\
(\mathrm{Kg})\end{array}$ \\
\hline Zinman et al. ${ }^{18}, 2015$ & 8.07 & $-0,24$ & 134.9 & $-2,6$ & 76.6 & $-0,3$ & 85.9 & $-1,1$ \\
\hline Tikkanen et al. ${ }^{\mathbf{1 9}}, 2015$ & 7.87 & $-0,65$ & 142.3 & $-3,78$ & 84.1 & $-1,52$ & 94.71 & $-1,72$ \\
\hline Barnett et al.20, 2014 (CKD II) & 8.02 & $-0,65$ & 137.4 & $-4,63$ & 76.5 & $-3,6$ & 92.1 & $-1,76$ \\
\hline Barnett et al. ${ }^{20}, 2014$ (CKD III) & 8.02 & $-0,42$ & 137.4 & $-4,3$ & 76.5 & $-1,5$ & 83.2 & $-1,17$ \\
\hline Barnett et al. ${ }^{20}, 2014$ (CKD IV) & 8.06 & 0,48 & 145 & $-12,2$ & 77.2 & $-5,7$ & 77.9 & -1 \\
\hline Bolinder et al. ${ }^{21}, 2014$ & 7.19 & $-0,42$ & NR & NR & NR & NR & 92.1 & $-2,42$ \\
\hline Matthaei et al. ${ }^{22}, 2015$ & 8.08 & $-0,69$ & 134.5 & $-3,7$ & 80.4 & NR & 88.6 & $-2,1$ \\
\hline Kohan et al. ${ }^{23}, 2014$ & 8.22 & $-0,34$ & 133.7 & $-6,04$ & 73.8 & $-0,36$ & 93.2 & $-3,63$ \\
\hline Leiter et al. ${ }^{24}, 2014$ & 8.18 & $-0,4$ & 133.5 & -3 & 77 & NR & 92.6 & $-1,9$ \\
\hline Neal et al. ${ }^{25}, 2015$ & 8.3 & $-0,72$ & 137.1 & $-4,9$ & 76.3 & $-1,9$ & 94.8 & $-3,1$ \\
\hline Yale et al. ${ }^{26}, 2014$ & 8 & $-0,41$ & 136.7 & $-6,09$ & 75.7 & NR & 90.4 & $-0,99$ \\
\hline Sinclair et al. ${ }^{27}, 2014$ & 7.9 & $-0,7$ & 134.3 & $-3,6$ & 75.9 & $-2,7$ & 90.2 & $-1,7$ \\
\hline Bode et al. ${ }^{28}, 2014$ & 7.75 & $-0,55$ & 130.8 & $-6,6$ & 75.5 & $-2,1$ & 88.6 & $-2,5$ \\
\hline
\end{tabular}

* Relative to placebo change and baseline levels. SBP: systolic blood pressure; DBP: diastolic blood pressure; NR: not reported.Figure Captions 
expression of SGLT2. Directly, early and still poorly explored findings have suggested that aging may reduce the expression of SGLT2 ${ }^{33}$. In order to verify these arguments, we assessed the effect of SGLT2i in elderly individuals and as shown in Figure 1, we found an overall decrease of $0.402 \%$ in HbA1c (95\% CI: -0.432, $-0.370 ; p<0.001 ; \mathrm{I}^{2}=0 \%$, which is overall comparable to findings in younger age groups ${ }^{15,17,24,27}$.

\section{Blood Pressure Reduction}

Although the coexistence of hypertension and T2DM could be related to their increased prevalence later in life, it may also stem from many common contributors such as aging, diabetic nephropathy, volume expansion, hyperinsulinemia, increased arterial stiffness, hyperglycemia ${ }^{34,35}$. More than 50\% of hypertensive individuals are older than 60 years; and among individuals older than 60 years, up to $67 \%$ have hypertension ${ }^{36}$. Typically, isolated systolic hypertension (ISH) is the most frequent type of age-re- lated hypertension and is responsible for up to $90 \%$ of cases in individuals older than $70^{37}$.

Arterial stiffness seems to be the main link between aging and ISH, and its mechanistic basis is strongly related to elastin fracture and increased collagen deposition in blood vessel walls ${ }^{38}$. Among diabetic individuals, the process of arterial stiffening is accelerated by the deposition of advanced glycation products like glyoxal and methylglyoxal, which are responsible for a number of collagen cross-links ${ }^{39}$. The binding of these glycation products with endothelial cells also induces cell signaling that results in oxidative stress, increased expression of cytokines and adhesion molecules, and activation of nuclear factor-kappa B (NF$\mathrm{kB})^{40}$. Similarly, modifiable causes such as endothelial dysfunction or those related to the metabolism of uric acid, calcium or potassium may influence the stiffness of conductance arteries leaving room for therapeutic interventions ${ }^{41}$. In fact, treatment with empagliflozin, which attenuates oxidative stress and improves endo-
A

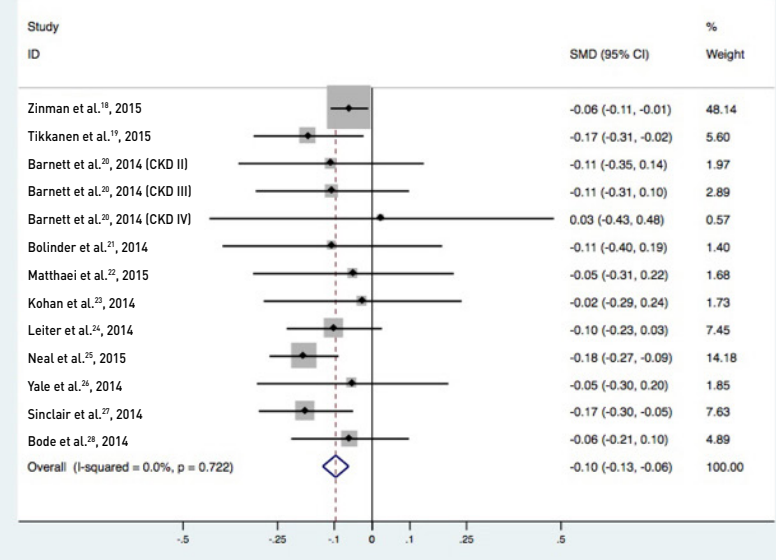

C

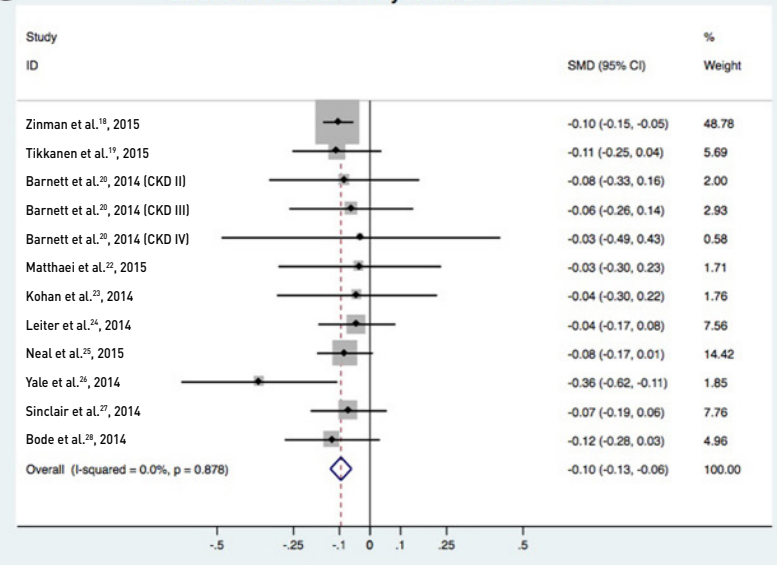

B Effect of SGLT2i on Body Weight Study
10 Zinman et at.'., 2015 Tikkanen et al. ${ }^{19}, 2015$ Barnett et at.20, 2014 (CKD III) Barnett et al.2., 2014 ICKD III Barnett et al.20, 2014 /CKD II)
Bolinder et al. ${ }^{21}, 2014$ Matthaei et al. ${ }^{22}, 2015$ Kohan et a.t.2, 2014 Leiter et at. lat, $^{2014}$ Neal et al. $2 ., 2015$ Yale et al. $2 ., 2014$ Sinclair et a a.".7, 2014 Sinclair et al. 2 , 2014 Overall (1-squared $=0.0 \%, p=0.660$ )

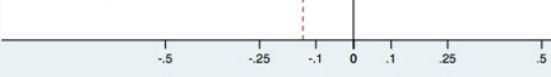

D Effect of SGLT2i on Diastolic Blood Pressure

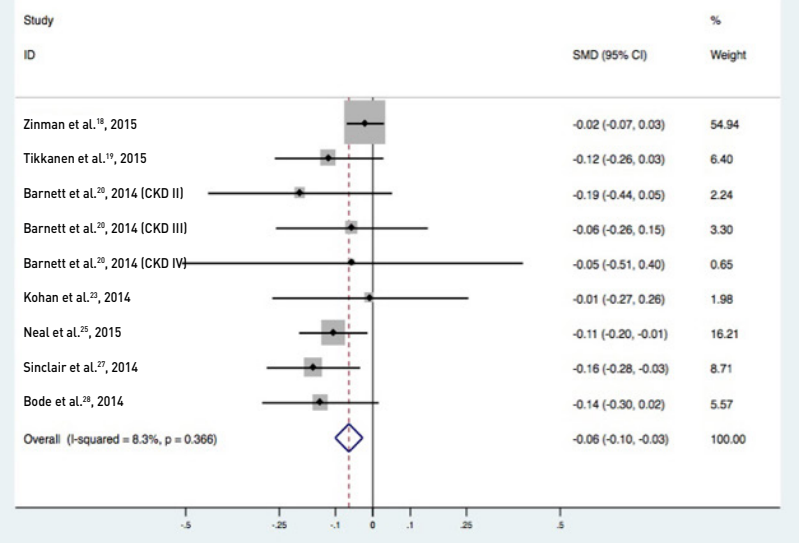

FIGURE 1. Meta-analysis of clinical trials mostly represented by individuals $>60$ years-old comparing SGLT2 inhibitors vs. placebo on (A) HbA1c, (B) Body weight, (C) Systolic blood pressure (SBP) and (D) Diastolic blood pressure (DBP). 
thelial function, has led to a reduction in both arterial stiffness and vascular resistency ${ }^{42-44}$.

In several studies, including some with older individuals, SGLT2i has reduced systolic $\mathrm{BP}^{17,27,28,42}$. For example, canagliflozin $300 \mathrm{mg}$ has led to a $7.5 \mathrm{mmHg}$ (95\% CI -9.8,-5.2) reduction in systolic BP compared to the placebo over a 104 weeks treatment ${ }^{17,27,28}$, which was consistent with further studies in individuals over 75 years-old treated with empagliflozin ${ }^{42}$. It is noteworthy that such an effect was independent of background therapies, such as metformin, sulphonylurea, GLP-1 agonists, and insulin ${ }^{22,25,45}$. Importantly, the magnitude of the effect achieved with SGLT2i is approximately half of that obtained with hydrochlorothiazide $25 \mathrm{mg}^{46}$, reaching a mean reduction in systolic BP of $3.45 \mathrm{mmHg}$ (95\% CI: (-4.10, -2.81); p $\left.<0.001 ; \mathrm{I}^{2}=43.2 \%\right)$. Although this effect may not reach clinical benefit alone, it could solve the problem of the increasing number of drugs or dose in the antihypertensive therapy ${ }^{47}$.

The effect of SGLT2i therapy on BP was tested on two specific trials, though none of these were exclusively performed on elders. The EMPA-REG BP trial assessed the efficacy of empagliflozin on BP reduction on hypertensive patients monitored by ambulatory BP monitoring (ABPM) using up to two hypotensive medications. The mean $24 \mathrm{~h}$ systolic $\mathrm{BP}$ on empagliflozin $25 \mathrm{mg}$ reduced by $4.16 \mathrm{mmHg}$ (95\% CI: -5.5, -2.83; $\mathrm{p}<0.001$ ) and diastolic BP by -1.72 mmHg (95\% CI: $-2.51,-0.93$; $p<0.0001)$ compared to the placebo ${ }^{19}$. In a similar trial performed on hypertensive diabetic patients using on angiotensin-converting-enzyme inhibitor (ACEi) or angiotensin II receptor blockers (ARB) plus other anti-hypertensive medication, dapagliflozin $10 \mathrm{mg}$ was associated to a mean 24-h systolic BP reduction of $4.28 \mathrm{mmHg}(95 \%$ CI: $-6.54,-2.02)^{48}$. This effect was similar across others antihypertensive medications such as thiazide diuretic, a calcium-channel blocker, and beta-blocker, though less intensive when dapagliflozin was added to thiazide diuretic ${ }^{48}$.

Different factors may contribute to BP reduction on SGLT2i therapy ${ }^{35}$. In the early stage, increased natriuresis and osmotic diuresis favor systolic BP reduction ${ }^{35}$. This is likely the reason why a reduction of BP was observed as soon as 1 week after treatment with dapagliflozin ${ }^{23}$. Plasma volume contraction of $-7.3 \%$ on dapagliflozin and $-5.4 \%$ on canagliflozin was observed early on during the treatment ${ }^{46,49}$. Paradoxically, this effect on BP is maintained while sodium excretion and diuresis tend to return to previous levels over the first 12 weeks ${ }^{19,49}$.

In addition to these effects, weight loss and glycemic control may also take part in the observed effect SGLT2i on $\mathrm{BP}^{35}$. Hyperglycemia is associated with up-regulation of SGLT2 and activation of both renin-angiotensin-aldosterone axis and sympathetic system $^{35}$. Even weight loss obtained exclusively by dietary treatment can reduce $\mathrm{BP}^{50}$, contributing in up to $28 \%$ of systolic BP reduction ${ }^{51}$.

Therefore, it seems possible that SGLT2i therapy could contribute to the control of the hypertension burden in older individuals. It is unlikely that this effect in BP will be the determinant factor for choosing these medications in the future, but they could pose as ancillary therapy.

\subsection{Weight loss}

Weight loss in older individuals is a debating theme. In the general population, obesity has been extensively associated with multiple comorbidities and an increased incidence of cardiovascular events. In the elderly, observational studies have reported that weight loss is associated with falls, disability ${ }^{52}$, increased morbidity ${ }^{53}$ and mortality ${ }^{52,54}$. Multiple adjustments have been made in these studies in order to mitigate the interference of confounders. Still, the inability to exclude the potential interaction by unapparent or unknown disease-mechanisms underlying such spontaneous weight loss has carried on this controversy.

Intentional weight loss was not associated with increased mortality during a 12-years follow-up in obese individuals older than 65 years ${ }^{55}$. In a cohort of older adults, weight loss due to psychosocial stress was not associated with increased mortality, though an adverse outcome was still associated with spontaneous weight $\operatorname{loss}^{56}$. Hence, it is conceivable that spontaneous and induced weight loss could not be the same; the latter may even be considered as a therapeutic target.

Studies with induced weight loss on elders have found improvement in both lipid profile ${ }^{57,58}$ and glucose metabolism ${ }^{57,59}$. In such studies, two-thirds of the weight loss is from fat and a third from lean tissue. While one might assume that this loss of lean body mass can trigger or intensify a loss of physical function, the results available indicate otherwise. In fact, the improvement of physical function is related to the amount of fat mass lost regardless of the amount of 
lean mass lost ${ }^{60}$. The muscle's fat content is inversely related to its strength and directly related to its decline over time ${ }^{61-64}$. Thus, reduced muscle strength is a reliable marker of mortality and loss of mobility independently of lean body mass ${ }^{65,66}$. Also, the proportional increase in lean mass is associated with a gain in bone mineral density, an improvement regarding frailty syndrome ${ }^{67}$ and a reduction in mortality ${ }^{68}$.

Although weight loss goals have not yet been established, this effect of SGLT2i in the elderly has been tested in different backgrounds. As seen in Figure 1, the pooled effect of SGLT2i therapy across trials with the elderly was of $-1.72 \mathrm{~kg}$ (95\% CI: -2.48 , $\left.-0.97 ; \mathrm{p}<0.0001 ; \mathrm{I}^{2}=38.3 \%\right)$. For instance, canagliflozin $300 \mathrm{mg}$ was associated with $3.0 \%(-2.7 \mathrm{~kg})$ weight loss at 26 weeks $^{28}$, which was maintained over 104 weeks ${ }^{17}$. Clinically relevant weight reduction (considered as $5 \%$ of weight reduction) increased by $23 \%$ with this treatment ${ }^{17,27}$. On individuals $\geq 65$ years, dapagliflozin induced a progressive weight reduction that reached $-3.4 \mathrm{~kg}$ at 52 weeks ${ }^{24}$.

This is also observed in individuals using medications associated with weight gain such as sulphonylurea or insulin, the addition of SGLT2i reduced body weight significantly ${ }^{22,25,69,70}$. Moreover, this effect is additive for other therapies associated with weight loss such as GLP-1 agonists ${ }^{45}$.

The amount of glucose lost through urine provides a deficit of 200-400 kcal/day. With such caloric loss during a long-term follow-up, one could expect that the weight loss would be more significant than what was actually verified. The increase in caloric intake71 partially explains this reduced expected effect ${ }^{1}$. Such a compensatory increase in the caloric intake is proportional to the glucose excretion ${ }^{71}$. Potentially, the association between SGLT2i and appetite suppression would provide a higher and longer weight loss than the use of these drugs as monotherapy.

Besides hyperphagia, SGLT2i treatment in mice was associated with a decrease in oxygen consumption and brown adipose tissue thermogenesis via down-regulation of an inter-organ neural network consisting of the common hepatic vagal branch and sympathetic nerves ${ }^{72}$. Together, the reduction of energy consumption and increased caloric intake promote a balance to caloric loss through urine that keeps the initial weight loss achieved with SGLT2i in the first few weeks till up to 208 weeks $^{73}$.

Regarding the effect of SGLT2i in body composition, over 102 weeks of dapagliflozin treatment, fat mass changed by $-1.34 \mathrm{~kg}(-2.44,-0.23)$ and lean mass changed by $-0.4 \mathrm{~kg}(-1.0,0.2)^{23}$. This led to a proportional change in body composition, with a decrease of $-1.5 \%(-2.1,-0.8)$ of fat mass and an increase of $1.3 \%(0.5,2.1)$ of lean mass ${ }^{21}$. In the mechanistic point of view, one possible explanation could be the effect of SGLT2i in increasing insulin sensitivity, thus favoring the anabolism of the muscle tissue $\mathrm{e}^{14,74}$.

Another issue yet to be clarified is the preferred effect of fat mass loss after SGLT2i in visceral or subcutaneous tissue. In a study using magnetic resonance imaging, the decrease in visceral adipose tissue (-258.4 $\left.\mathrm{cm}^{3}(-448.1,-68.6)\right)$ tended to be higher than that on subcutaneous adipose tissue $\left(-184.9 \mathrm{~cm}^{3}\right.$ (-359.7, -10.1)), though this difference did not reach statistical significance in up to 102 weeks of treatment ${ }^{21,74}$.

\section{EFFECT ON KIDNEY AND RENAL DISEASE PROGRESSION}

As a result of the natural decline in glomerular filtration rate (GFR), the elderly often present clinically relevant renal dysfunction, particularly with diabetes. Indeed, chronic kidney disease (CKD) affects more than $50 \%$ of individuals over 70 years ${ }^{75}$. Although less than $2 \%$ of stage 3 CKD patients require renal replacement in mid-term follow-up (8 years) ${ }^{76}$, almost half end-stage kidney disease is attributed to $\mathrm{DM} 2^{77}$. The relative risk of death and progression of end-stage renal disease is increased in elders with low GFR and high albuminuria, though its corresponding effect on mortality wanes at an older age ${ }^{78}$.

Aging induces changes in the kidney as compared to a disease that occurs in some but not all individuals. The microanatomical structural changes of the kidney with older age include a decreased number of functional glomeruli from an increased prevalence of glomerulosclerosis, arteriosclerosis and tubular atrophy with interstitial fibrosis and compensatory hypertrophy of remaining nephrons. Among carefully screened healthy kidney donors, glomerular filtration rate (GFR) declines at a rate of $6.3 \mathrm{~mL} / \mathrm{min} / 1.73$ $\mathrm{m}^{2}$ per decade. The elderly have less kidney functional reserve when they do actually develop CKD, and they are at higher risk for diabetic kidney disease and its progression $^{79}$. Diabetes accelerates these age-related changes leading to a higher functional decline and precocity $^{80,81}$. In fact, senescent tubular phenotype cells could be induced by high glucose concentrations ${ }^{82}$, and these alterations on tubular proximal cultured 
cells are associated with increased expression of SGLT2 ${ }^{83}$.

Increased glomerular filtration is one of the earlier markers of diabetic nephropathy. The renin-angiotensin system (RAS) plays a significant role in glomerular hyperfiltration on diabetic nephropathy. Glucose can induce angiotensin II (AngII) generation by local activation of $\mathrm{RAS}^{84}$, constriction of efferent arteriole thus influencing sodium reabsorption and increasing glomerular permeability ${ }^{85}$.

Similarly, the increased sodium reabsorption through SGLT2 may also contribute to renal hyperfiltration. SGLT2 expression is increased at the proximal tubule of diabetic experimental models ${ }^{86}$ and in diabetic patients ${ }^{87}$. This promotes a reduction of sodium on macula densa, thus increasing vasodilation on afferent arteriole ${ }^{88}$. The therapeutic use of SGLT2i increases the sodium delivery to the macula densa, thus decreasing $\mathrm{GFR}^{89}$. In parallel, other mediators participate in the regulation of renal hemodynamics, such as adenosine, nitric oxide, and calcium influx, contributing to the glomerular filtration rate. Thus, the hyperfiltration of diabetic kidney disease and its control will depend on the outcome of the balance of this set of players.

On aging CKD patients, an increased rate of nephron loss units is observed. In parallel, there is an adaptive decrease in SGTL2 transcription rate ${ }^{90}$ and, consequently, a decrease in SGLT2i effectiveness on CKD patients, as SGLT2i acts on the extracellular surface of the tubule lumen celli1. Therefore, clinical trials on SGLT2i observed reduced effectiveness on glycemic control. A progressive decline on HbA1c effectiveness was reported on empagliflozin $25 \mathrm{mg}$ in individuals with CKD stage $2(-0.68 \%)$, to stage 3 $(-0.42 \%)$ and to stage $4(+0.04 \%)^{20}$. An investigation of dapagliflozin effect on CKD individuals indicated that the cut-off point for the decline of SGLT2i glucose-lowering effect is GFR $\leq 45 \mathrm{~mL} / \mathrm{min}^{23}$. In the general population, the concomitant inhibition of SGLT1 and SGLT2 increases the glycosuria as compared with the isolated inhibition of SGLT2 ${ }^{92}$. In CKD patients, however, a head-to-head comparison of their effect is unavailable.

Hypertension is the most common comorbidity among CKD patients and its prevalence increases as renal function worsens ${ }^{93}$. Particularly in this population, BP controlling could attenuate the progression of kidney disease ${ }^{94}$. On stage 3 and 4 CKD, SGLT2i therapy reduced SBP by - $5.46 \mathrm{mmHg}$ (95\% CI: -7.83, $\left.-3.07 ; \mathrm{p}=0.001 ; \mathrm{I}^{2}=0 \%\right)$. SGLT2i therapy was associated with a reduction on SBP and DBP by $52^{20,23,26}$ and 104 weeks $^{23}$ among CKD patients. As with glycemia, empagliflozin effects on BP wane as renal insufficiency worsens ${ }^{20}$.

On CKD patients, not only the above-cited mechanisms could be beneficial; body weight management is associated with hindering proteinuria and the prevention of GFR decline ${ }^{95}$. Indeed, SGLT2i therapy is associated with body weight reduction in CKD patients, which is inversely proportional to the severity of renal dysfunction ${ }^{92}$. This coupling is consistent with the reduced tubular expression of SGLT2 and the glycosuria induced by SGLT2i, which is proportional to the decline in GFR.

Probably as a consequence of constriction of the proximal arteriole, eGFR decreases by approximately $4 \mathrm{~mL} / \mathrm{min} / 1.73 \mathrm{~m}^{2}$ on the general population and older patients ${ }^{96}$. The magnitude of the reduction on GFR during SGLT2i therapy is similar to that observed after distal arteriole dilation by $\mathrm{ACE}^{88,97}$. This effect is observed as soon as after 1 week $^{98}$ and tended to return to baseline values during follow-up ${ }^{17,96,98}$, though persistent reductions can be observed ${ }^{25}$. During SGLT2i therapy, older patients had similar or slightly higher reductions of eGFR compared to their younger counterpart ${ }^{27,96,98}$. However, even though aging does not significantly influence the variation in absolute GFR values, the percent loss of renal function may be higher due to preexisting renal dysfunction often found in the elderly ${ }^{96,99}$. Even though, a clinically significant decrease of GFR (at least 50\%) is infrequent even in Stage 3 CKD $(12.2 \%)^{96}$.

Since the approval of the first SGL2i in March 2013 until October 2015, the FDA received reports of 101 confirmed cases of acute kidney injury (canagliflozin=73, dapagliflozin=28). Hospitalization and need of dialysis were required for a selected number of patients. Most improved with the discontinuation of the drug. There were no signs of direct drug toxicity, and most cases were observed in patients with predisposing factors to pre-renal AKI: decreased blood volume, chronic kidney insufficiency, congestive heart failure, concomitant medications such as diuretics, ACEi, ARBs, NSAID. The warning reinforces that the patient's kidney function should be assessed prior to starting treatment and be monitored periodically after that before being started on SGLT2 therapy. Also, one should consider temporarily discontinuing treatment in any setting of severe acute illness, prolonged fast- 
ing, or severe fluid losses. If acute kidney injury occurs, the drug should be discontinued promptly.

\section{SAFETY CONCERNS}

Volume-depletion-related events

Adverse events (AE) related to volume depletion are of particular concern of this drug class. As it would be expectable, SGLT2i therapy induces plasma volume contraction through its effect on the proximal tubular cells. An increase in 24-h urine output of approximately $370 \mathrm{~mL}$ and up to $10 \%$ contraction of plasma volume have been reported on this treatment ${ }^{46,49,100,101}$. Whether or not and in what degree the plasma volume returns to baseline levels during therapy is still a debated theme ${ }^{46,49}$. However, safety concern on volume depletion has been assessed in recent clinical trials.

In safety clinical trials, volume depletion has been characterized by postural dizziness, orthostatic hypotension, increased in heart rate, dehydration, hypotension, orthostatic hypotension, pre-syncope, and syncope. In 104 weeks, the incidence is reported to be $5.9 \%$ on canagliflozin ${ }^{17}$.

Probably as a consequence of plasma volume contraction, RAS activity and aldosterone levels are increased during SGLT2i therapy ${ }^{46}$. Actually, an elegant study demonstrated that during SGLT2i therapy there is an increase in both systemic and intrarenal RAS activity ${ }^{97}$. It is established the proatherosclerotic role of the RAS axis activation via a spectrum of mechanisms including inflammatory pathways, insulin resistance, hypertension, and oxidative stress $^{102}$. The long-term effects of these pathways' activation with SGLT2i remain to be assessed. In the only published study in which the cardiovascular effect of SGLT2i was tested, about $80 \%$ of patients were on concomitant use of RAS inhibitors ${ }^{18}$. By presumption, it would be gainful to associate RAS inhibitor therapy with SGLT2 $\mathrm{i}^{48,49}$.

The incidence of volume-depletion-related $\mathrm{AE}$ is low, but it may increase as renal function worsens. For example, the incidence after empagliflozin is 1.0\% on stage $2,3.7 \%$ on stage 3 CKD and $5.4 \%$ on stage $4^{20}$. Likewise, the incidence of volume depletion $\mathrm{AE}$ is dose-dependent ${ }^{103}$ and increased overtime ${ }^{26,99}$. There is no apparent influence of the concomitant use of anti-hypertensive medications ${ }^{19}$ or even thiazide therapy on the incidence of these $\mathrm{AE}^{48,104}$. Among the elderly, special attention must be paid to orthostatic hypotension, whose incidence is increased in up to $9 \%$ after SGLT2 ${ }^{19}$.

\section{Osmotic diuresis-related AE}

Since long-term therapy with osmotic diuresis became available for clinical practice for the first time after SGLT2i development, the pros and cons of this therapy remain theoretical. Potential AE includes pollakiuria, polyuria, dry mouth, dry throat, micturition urgency, nocturia, polydipsia, and increased thirst, among others. So, particular attention must be paid on elderly individuals to be treated by SGLT2i whose baseline pre-treatment condition is already associated with some of these symptoms. Osmotic diuresis symptoms are dose-related ${ }^{28}$, GFR-influenced $\mathrm{d}^{23,26,96,99,103}$ and time-dependent, raising up to $12.3 \%$ over 104 weeks ${ }^{17}$. Also in patients in use of therapies associated with sodium retention such as insulin and sulfonylurea, similar rates of osmotic diuresis AE have been report$\mathrm{ed}^{25,45}$. However, a SGLT2i-induced 3-fold rise (from 0.1 to $0.3 \%$ ) in the incidence of volume-related $\mathrm{AE}$ were previously reported ${ }^{98}$.

\section{Diabetes Ketoacidosis}

A particular type of diabetic ketoacidosis (DKA) has been reported during SGLT2i therapy which differs from the usual form by the attenuated expression of hyperglycemia and ketonuria; the called euglycemic DKA (eDKA). On a pooled analysis, eDKA frequency was overall low but slightly higher on SGLT2i (2-3 times) than with other anti-diabetic therapies ${ }^{18,105}$.

SGLT2i therapy increases ketonemia in a dose-dependent manner via a spectrum of mechanisms ${ }^{\mathbf{1 0 6}}$. In animal and cell models, SGLT2i therapy induces ketone production by directly inducing glucagon secretion by alpha pancreatic cells ${ }^{107}$. Consistently, in clinical studies, hepatic glucose production is up-regulated after SGLT2i treatment ${ }^{14,16}$, at least in part due to the increase in glucagon levels stimulating hepatic ketogenesis and gluconeogenesis ${ }^{108}$. Likewise, SGLT2i increases the risk of eDKA by augmenting ketone absorption and reducing ketonuria ${ }^{108}$.

Among the reported eDKA cases, a high proportion of individuals had concurrent conditions which may increase their susceptibility, such as of autoimmune diabetes, reduction of insulin background therapy and acute illness ${ }^{105}$. Moreover, the eDKA cases were one decade older than their counterparts, and at least $50 \%$ had late autoimmune diabetes on adults (LADA) $)^{109}$, while the prevalence of LADA is up 
to $10 \%$ on diabetic population ${ }^{110,111}$. Thus, although the incidence of eDKA during SGLT2i is low $(1.3 / 1000$ patients-year), the possibility of this diagnosis must be borne in mind particularly among the elderly and those insulin-requiring ${ }^{109}$.

\section{Hypoglycemia}

In elderly diabetics, the casual detection of hypoglycemia indicates a fourfold increase in the risk of death, which is a risk predictor even greater than pre-existing ischemic heart disease ${ }^{12}$. Beyond that, in this age group hypoglycemia is associated with an increased risk of fall ${ }^{113}$, fracture ${ }^{114}$, and cognitive decline $^{115,116}$

From a pathophysiological point of view, direct and indirect effects of hypoglycemia ensues a set of metabolic, thrombotic, inflammatory and vasomotor effects, favoring the remodeling of atherosclerotic plaques to an unstable phenotype and its thrombotic occlusion. In the short term, hypoglycemia can reduce the energy source for myocardial cells, particularly in individuals with diabetes or ischemic heart disease, prolonging QT interval, a substrate for life-threatening ventricular arrhythmias. In the elderly, impaired counter-regulatory mechanisms may result in higher susceptibility to hypoglycemia's duration and its deleterious effects ${ }^{117}$. Consistent with the short-term effect, while the blood glucose decreased by about $16 \%$ the risk of nonfatal myocardial infarction, the incidence of cardiovascular death is not reduced.

SGLT2i therapy in the elderly did not increase the risk of hypoglycemia. The relative risk of hypoglycemia was 1.11 (95\% CI: 0.84, 1.45; $\mathrm{p}=0.554 ; \mathrm{I}^{2}=0 \%$ ) across SGLT2i and comparators on patients on a background therapy not prone to hypoglycemia, as seen in figure 2A. Hypoglycemia was not described slightly more often when SGLT2i was added to a background prone to hypoglycemia (insulin or sulphonylurea), posing a RR of 1.05 (95\% CI: 0.99, 1.11; p $=0.198 ; \mathrm{I}^{2}=39.1 \%$ ) (Figure 2B), although considerable heterogeneity was observed. Although hypoglycemic adverse events were higher on SGLT2 inhibitors when compared to the placebo, these AE were much higher on insulin or sulphonylurea therapy backgrounds. It is also described as an increase of hypoglycemic AE when renal function worsens. However, specifically on the elderly, there are no head-a-head trials of other hypoglycemic therapies vs. SGLT2i. Therefore, although it is possible that SGLT2i could reduce hypoglycemia rates in comparison to other drugs on older individuals, more studies are needed to assess this issue.

In stage 3 or 4 CKD individuals, hypoglycemia rate was similar among SGLT2i and placebo on individuals not on hypoglycemia prone therapy, with RR of 1.01 (95\% CI 0.75, 1.37; $\mathrm{p}=0.688 ; \mathrm{I}^{2}=0 \%$ ), though on insulin or sulphonylurea background therapy RR was 1.05 (95\% CI: 0.85, 1,30; $\mathrm{p}=0.311 ; \mathrm{I}^{2}=57 \%$ ) with substantial heterogeneity among trials in this last comparison. Comparing the effect of empagliflozin on different stages of CKD, progressively renal impairment was associated with higher rates of hypoglycemia ${ }^{20}$. In fact, stage 4 CKD on empagliflozin had an incidence of $37.8 \%$ of hypoglycemic $\mathrm{AE}$ vs. $32.4 \%$ on placebo, but lower incidence of AE were noted on stage 3 CKD ( $27.8 \%$ vs. $28.3 \%$ on empagliflozin and placebo, respectively) or stage 2 CKD (22.7\% vs. $26.5 \%$ vs. $24.2 \%$ on empagliflozin 25 and $10 \mathrm{mg}$ and placebo, respectively) ${ }^{20}$.

\section{Genital urinary-tract infections}

Urinary tract infections (UTI) incidence is higher on older TSDM females, specifically those with poorly controlled diabetes ${ }^{118}$. Actually, in T2DM, moderate to severe glycosuria is associated with asymptomatic bacteriuria and also to pyelonephritis ${ }^{119}$. As a concern of diabetic and older individuals and because of increased glycosuria on SGLT2i therapy, most of the clinical trials and reviews involving SGLT2 inhibitors reported UTI and GTI incidences ${ }^{117-122}$.

As observed in Figure 3, SGLT2i therapy did not increase the incidence of UTI events in trials with elderly individuals. The RR of uncomplicated and complicated UTI on SGLT2i therapy was respectively 1.04 (0.95, 1.14; $\left.\mathrm{p}=0.186 ; \mathrm{I}^{2}=24.9 \%\right)$ and 0.93 (0.66, 1.31; $\left.\mathrm{p}=0.745 ; \mathrm{I}^{2}=0 \%\right)$. However, as expected on SGLT2i therapy, females had a higher risk of GTI, with a RR of 4.13 (2.96, 5.76; $\mathrm{p}<0.001 ; \mathrm{I}^{2}=32.6 \%$ ), while males had a RR of 4.02 (2.91, 5.57; $\left.p<0.001 ; \mathrm{I}^{2}=0 \%\right)$. However, few participants discontinued medication due to this $\mathrm{AE}$, and the majority of GTI and UTI are benign conditions that were resolved with appropriate medication.

The overall incidence of UTI was higher on EMPAREG trial than others (on females, $40.6 \%$ on placebo and $36.4 \%$ on empagliflozin; on male individuals, $9.4 \%$ on placebo and $10.4 \%$ on empagliflozin). Paradoxically, the placebo branch had higher rates of complicated urinary tract infections than the empagliflozin (1.8\% vs. 1.7\%), though urosepsis developed on 17 individuals on empagliflozin and 3 on placebo $^{18}$. The RR of UTI on CKD patients was 1.09 (0.83, 1.44; 
$\mathrm{p}=0.517)$. Similar to that of subjects without renal disease, RR of GTI was 2.31 (95\% CI: 1.13, 4.75; $\mathrm{p}=0.22$ ) on males and 4.00 (95\% CI: 1.62, 9.86; $\mathrm{p}=0.003)$ on females on SGLT2i therapy.

A

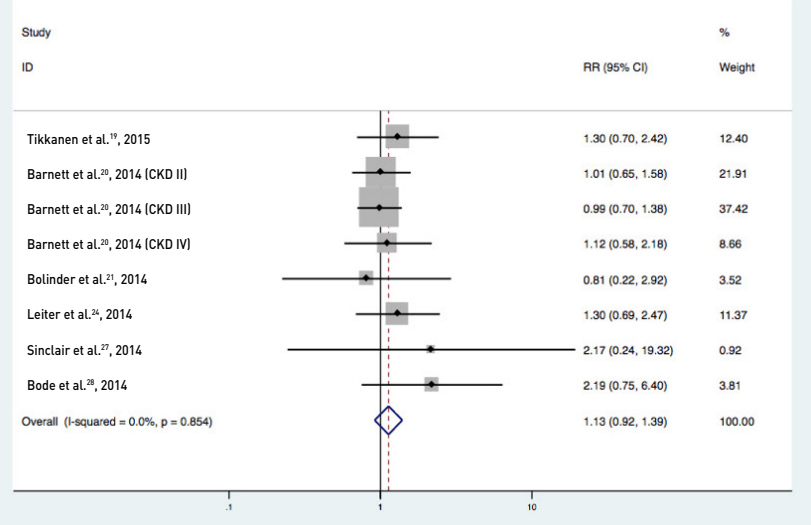

\section{Bone Metabolism}

From the fifth decade of life, there is a progressive loss of bone mass, which may reach the osteoporosis degree according to the peak of bone mass achieved,

B

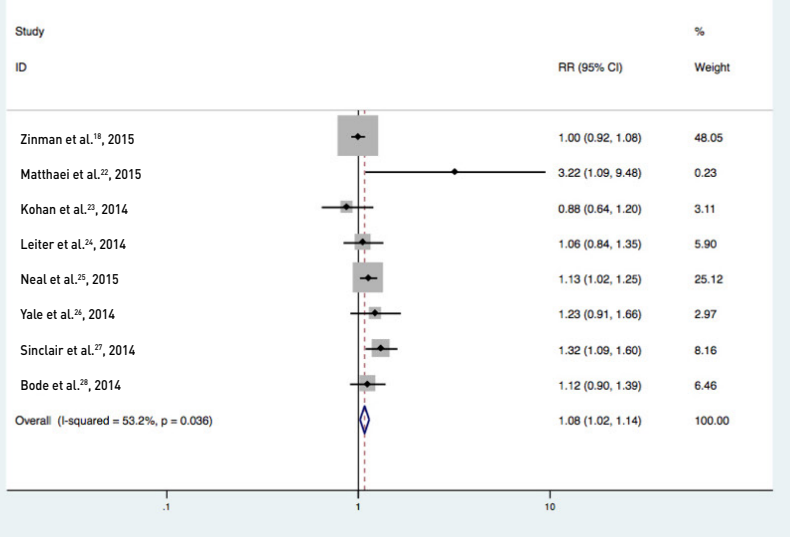

FIGURE 2. Meta-analysis of clinical trials in individuals >60 years-old comparing SGLT2 inhibitors vs. placebo on (A) Hypoglycemic events in patients not on background insulin or sulphonylurea therapy, (B) Hypoglycemic events in patients on background insulin or sulphonylurea therapy.
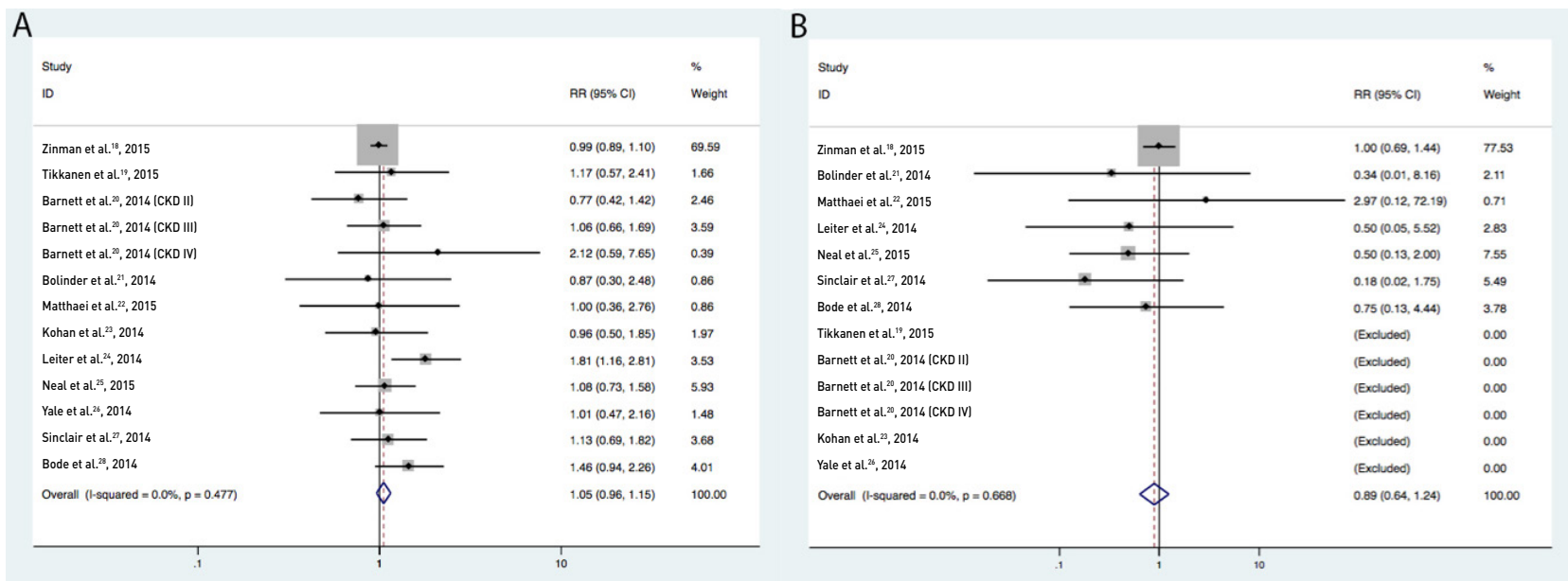

C

\section{Study \\ ID}

Zinman et a.. ${ }^{18}, 2015$ Tikkanen et al. 19,2015 Barnett tet al., 2014 (CKD II) Barnett et al. ${ }^{20}, 2014$ (CKD III) Bolinder et at."2, 2014 Matthaei et at. $.^{22}, 2015$ Kohan et a. a., 2014 Leiter et a.2.2, 2014 Neal et a $1.5,2015$ Yale et al. ${ }^{25,}, 2014$ Sinclair et at..27, 2014 Bode et a..2., 2014 Barnett et al. ${ }^{20}, 2014$ (CKD IV) Overall (1-squared $=2.9 \%, p=0.416$ )
D

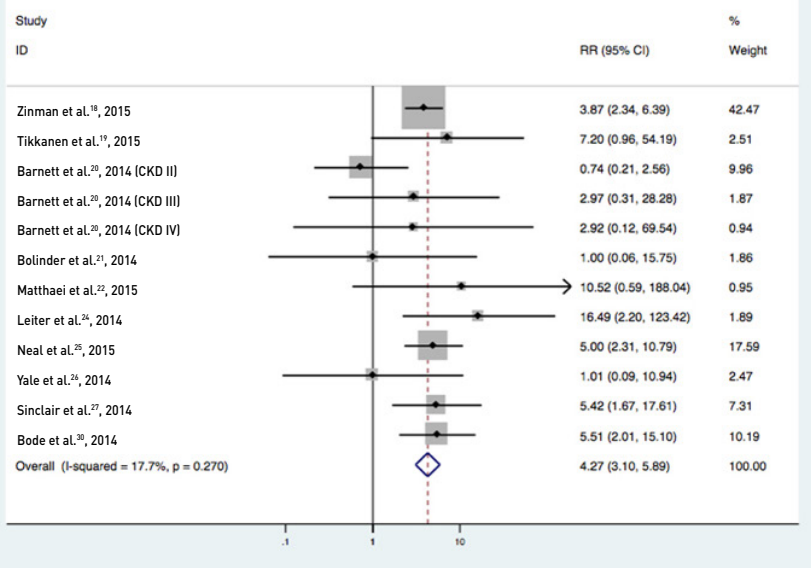

FIGURE 3. Meta-analysis of clinical trials in individuals $>60$ years-old comparing SGLT2 inhibitors vs. placebo on (A) uncomplicated urinary tract infection (UTI), (B) complicated UTI events, genital tract infection (GTI) events in males (C) and females. (D) 
the rate of bone loss and longevity. Genetic factors, hormonal status, physical inactivity, low calcium intake, low sun exposure, smoking and comorbidities such as CKD and DM2 may all contribute to an accelerated deterioration of bone mass; thus, they may favor the risk for osteoporotic fragility fracture. In parallel, regardless of the bone mineral density (BMD), individuals with T2DM may have an osteopathic disease with significant changes in bone quality and architecture $^{123}$. Finally, T2DM is also associated with increased risk of fractures among the older population due to peripheral neuropathy and increased risk of falls ${ }^{124}$.

In regards to pharmacodynamics of SGLT2i, this therapy may favor mineral and electrolytes disturbances, which can further contribute to the rate of bone loss by increasing phosphate, calciuria and production of parathyroid hormone (PTH) and fibroblast growth factor 23 (FGF23) ${ }^{125}$. In up to 50 weeks, SGLT2i treatment on subjects $\geq 60$ years presented no significant differences between SGLT2i therapy and the placebo on markers of bone reabsorption, such as procollagen type $1 \mathrm{~N}$-terminal propeptide and C-terminal cross-linking telopeptides of type I collagen ${ }^{\mathbf{2 2}}$. However, on a longer follow-up of 104 weeks, different bone turnover markers such as $\beta$-carboxy-telopeptide and osteocalcin were increased with SGLT2i therapy ${ }^{127}$. However, the increased bone turnover does not seem to impact on BMD of the femoral neck, lumbar spine, and total hip after 50 weeks ${ }^{126}$ or 104 weeks $^{21}$ of SGLT2i.

In a recent trial performed on individuals between $55-80$ years, canagliflozin was associated with a $1.2 \%$ decrease in total hip BMD over 104 weeks, though not on other sites measured ${ }^{127}$. Despite the hypothesis-generating nature of the study, the possibility of a more significant impact on the decline in bone mass after SGLT2i was raised by these findings. It is not plausible that it could be a direct action of the drug since SLGT2 is not expressed on bone cell types ${ }^{128}$. It is possible that the decrease in BMD is attributable to weight loss. On a post hoc analysis, $40 \%$ of BMD decline could be attributed to weight loss ${ }^{127}$. Similar results were observed in other weight loss situations ${ }^{129}$.

In the animal model, prolonged treatment with canagliflozin was associated with trabecular bone deterioration $^{125}$. However, in subjects with T2DM treated for a long time, improved glycemic control and insulin resistance attenuation can compensate an initial loss in bone calcification. In fact, oral hypoglycemic drugs are generally safe on clinical trials ${ }^{129}$. Few clinical trials have assessed bone health and the majority has reported fracture as an adverse event, posing a limitation to accurate analysis. Thus, a clearer picture of the mechanisms and clinical implications of the interaction between the inhibition of SGLT2 receptors and bone metabolism is still pending.

Another aspect to be considered in this scenario is diabetic osteopathy leading to weakness from BMD-independent structural changes in the bone ${ }^{130}$. Thus, the hard endpoint to be considered during clinical trials or in real life situations must be the incidence of fractures. In patients $\geq 65$ years, the incidence of fractures was higher on the placebo branch than on dapagliflozin $(2.7 \% \text { vs. } 0.4 \% \text {, respectively })^{24}$. In a pooled analysis of canagliflozin trials, the incidence of fractures was similar in both canagliflozin and the placebo, $2.7 \%$ vs. 1.9 (HR 1.32 [1.00-1.74]), respectively. However, in a subpopulation of high cardiovascular risk patients, canagliflozin was associated with a higher incidence of fracture ( $4 \%$ vs. $2.6 \%)$, possibly due to increased incidence of falls, as volume-related $\mathrm{AE}$ were more frequent on canagliflozin than on placebo (HR 1.76 (1.27-2.44)) $)^{131}$. Possibly endorsing fall-related fractures, this incidence was higher early on the beginning of treatment, and the fracture sites were the fists and feet. A sensitivity analysis including only osteoporotic fractures showed a similar risk increase of with canagliflozin ${ }^{131}$. It was also observed on the SGLT2i group a tendency (RR 1.30 (1.00-1.68)) to increase the risk of stroke, and this could be related to the risk of falls, especially for the elderly ${ }^{132}$. Therefore, it is possible that fractures related to SGLT2i therapy are associated with volume depletion.

In individuals with increased susceptibility to fractures due to osteoporotic fragility such as CKD patients, there is no clear evidence of an adverse effect of SGLT2i therapy. The incidence of fractures on CKD patients was indeed lower on canagliflozin 300 $\mathrm{mg}(1.1 \%)$ than on the placebo $(2.2 \%)$ over 104 weeks ${ }^{26}$. Patients on empagliflozin had a reduced number of fractures compared to those on the placebo with progressive renal failure from stage 2 to $3 \mathrm{CKD}^{20}$. Although one study observed higher rates of fractures with dapagliflozin (7.7\%), all reported events were related to trauma, and only 2 were considered severe adverse events ${ }^{23}$.

In conclusion, although the available data are insufficient to confirm or exclude a specific deleterious 
effect of these drugs on bone metabolism, falls due to hypovolemia were reported and the risk of falling should be considered in therapy indication with SGLT2 or SGLT2 / SGLT1 in elderly individuals.

\section{Effect on mortality}

Recently, the EMPA-REG Outcome trial showed a decrease in all-cause and cardiovascular mortality after the short-term use of SGLT2i in high-risk diabetic individuals ${ }^{18}$. Although SGLT2i could have a positive influence on cardiovascular risk factors (i.e., HbA1c, systolic BP, weight excess), the role of SGLT2i on survival improvement via atherosclerotic risk is unlikely. In this trial, for each non-fatal myocardial infarction prevented with empagliflozin three cardiovascular deaths were spared. This number speaks for itself against the attenuation of atherosclerosis as the primary mechanism of benefit. In fact, in statin trials, for each nonfatal myocardial infarction prevented 0.5 cardiovascular deaths are spared $^{133}$. Moreover, the early opening of the survival curves in about one month is unlikely a consequence of complex, long-lasting phenotypic changes such as stabilization of atherosclerotic plaques.

Potentially, a change in the heart-kidney crosstalk would favor the SGLT2i effect on cardiovascular mortality. Several mediators for this crosstalk have been reported, many with apparent impact on survival. Fibroblast growth factor $23(\mathrm{FGF} 23)^{134}$, renalase $^{135}$, asymmetric dimethylarginine (ADMA), erythropoietin, trimethylamine-N-Oxide (TMAO) and PTH are among the most studied players. As noted above, with aging there is a progressive decline in GFR generating an imbalance in the heart-kidney crosstalk in favor of increased cardiovascular risk. In fact, in the EMPA-REG trial ${ }^{18}$, there was a significant interaction between age and cardiovascular benefit provided by SGLT2 inhibition, which was higher among those with 65 years or older.

Looking from a different perspective, as a co-transporter of sodium and glucose, its inhibition can hypothetically reduce the sodium influx into cardiomyocytes reducing the propensity for life-threatening ventricular arrhythmias ${ }^{136}$. Consistent with this finding, the risk of sudden death was about $30 \%$ lower in those treated with SGLT2i ${ }^{18}$. Both aging ${ }^{137}$ and $\mathrm{T}_{2} \mathrm{DM}^{138}$ increase the incidence of sudden cardiac death ${ }^{8}$; the severity of coronary artery disease and hypoglycemia are mediators of the risk in both cases. In disagreement with this assumption, although the evidence is still scarce, studies in humans have indicated that SGLT1 is the predominant receptor in the myocardium and small intestine, while SGLT2 is predominant in the kidney $^{139}$. We still do not know if the proportion of SGLT1 and SGLT2 in the myocardium changes during the life course or under different stimuli. So far, aside from canagliflozin, other SGLT inhibitors have had minimal effect on the SGLT1 ${ }^{140}$.

In subjects with $\mathrm{T}^{2} \mathrm{D}^{141}$ or heart failures $(\mathrm{HF})^{142}$, the liver converts abundant plasma FFA into ketone bodies (KB) such as acetoacetate and 3-hydroxybutyrate. This KB excess in plasma is highly absorbed in the myocardium and in a dose-dependent manner is converted to acetyl-CoA ${ }^{143}$. In rodents, $\mathrm{KB}$ is used as the primary source of energy by cardiac cells ${ }^{144}$, and such use might hypothetically occur in individuals with T2D and heart failure, favoring the improvement in energy reserves ${ }^{141}$. Nevertheless, it is also possible that overfeeding myocardium with KB may induce insulin resistance and block the citrate cycle, thus reducing the power supply ${ }^{143}$. This controversy has been highlighted recently with the confrontation of two SGLT2i effects: increasing plasma KB and decreasing cardiovascular mortality in individuals with T2D and HF. In healthy elderly individuals, the KB output is similar to that in younger adults ${ }^{145}$. However, as commented above, among diabetic elderlies, the KB production tends to be increased due to insulin deficiency and malnutrition ${ }^{109}$. Hence, if this mechanism is in fact involved in the SGLT2i effects, elderly diabetic patients will be among the most improved populations.

\section{Effect on stroke}

A neutral or even beneficial effect has been reported with hypoglycemic therapies in stroke risk ${ }^{146}$. The possibility of benefits concerning stroke risk becomes even more likely if we consider the reduction of systolic blood pressure during treatment with SGLT2i ${ }^{147}$. However, despite the clear cardiovascular benefit SGLT2i, some concern was raised with a tendency to increase the incidence of stroke. In the EMPA-REG Outcome trial, the incidence of stroke tended to increase by $24 \%$ (95\% CI $0.92,1.67 ; p=$ $0.16)^{18}$. Considering the EMPA-REG trials outcome together with phase 2 or 3 studies, the risk of stroke increased by 30\% (95\% CI: 1.00, 1.68; p=0.049) ${ }^{132}$. An overall set of mechanisms that may be behind this potential adverse effect is unclear. However, ortho- 
static hypotension ${ }^{148}$, hemoconcentration ${ }^{149}$ and increased activity of renin-angiotensin-aldosterone system (RAAS) $)^{150}$ are among consequences of SGLT2i therapy that would favor stroke incidence.

In the elderly, this potential adverse effect may have greater significance for the natural propensity to hemoconcentration and orthostatic hypotension. To date, however, the relationship between the SGLT2i and the risk of stroke remains hypothetical as the number of events is small and only one prospective outcome-driven trial analysis is published. Two other studies are underway with dapagliflozin and canagliflozin, and its completion will help to discern more clearly this finding.

\section{CONCLUSION}

Few studies performed pre-specified analysis on the elderly. Therefore, to accurately assess its effects in older individuals, prospective studies are necessary. SGLT2i therapy is associated with glycemic effects on older individuals that are similar to younger ones. Similar effects on BP and BW have also been observed. In fact, as intentional body weight is not associated with higher $\mathrm{AE}$, it is plausible that drug-induced decrease on BW would have no increase in mortality. One limitation of these new agents is the higher prevalence of CKD on older individuals that could, in turn, reduce effectiveness. Other safety concerns are being outlined recently. DKA could influence SGLT2i prescription on insulin users but is rare on other individuals. Few cases of urosepsis were described on the largest SGLT2i trial to this date, and it is possible that this low number will be maintained in the long-term. The forthcoming studies regarding the cardiovascular safety of these new agents may establish this class as a top second- or first-line option in diabetes therapy.

\section{RESUMO}

A prevalência da diabetes mellitus tipo 2 em idosos cresceu muito na última década. A redução na sensibilidade à insulina e na capacidade secretora, ganho de peso, sarcopenia e adiposidade elevada são todas alterações metabólicas e corporais comuns entre a população idosa. Essas mudanças críticas favorecem o aumento no risco de hipoglicemia, síndrome de fragilidade, quedas e disfunções cognitivas. A primeira linha de tratamento contra a diabete muitas vezes não é segura para indivíduos mais velhos devido ao alto risco de hipoglicemia e a prevalência de comorbidades patogênicas, como doença renal crônica, osteoporose, doença cardiovascular e obesidade. Os inibidores do cotransportador sódio-glicose 2 (SGLT2) são uma nova classe de tratamento contra a diabete que inibe reabsorção de glicose e sódio na parte convoluta do túbulo proximal. Seu efeito é claramente demonstrado em diversos cenários clínicos em populações mais jovens. Esta revisão e meta-análise descreve as particularidades dos SGLT2 na população idosa, abordando os mecanismos dos potenciais benefícios e desafios ainda presentes do uso destes medicamentos nesse grupo etário tão importante. Além disso, apresentaremos uma meta-análise dos principais efeitos dos SGLT2 encontrados em estudos post-hoc nos quais a idade média dos subgrupos analisados foi acima de 60 anos. Apesar da ausência de ensaios clínicos que incluem essa população, os dados encontrados sugerem que o tratamento com SGLT2 em idosos é eficaz para diminuir os níveis de glicose e tem efeitos na pressão arterial sistólica e no peso corporal.

PALAVRAS-CHAVE: Transportador 2 de glucose-sódio/antagonistas e inibidores. Diabetes mellitus. Idoso. Eficácia.

\section{REFERENCES}

1. Viljoen A, Sinclair AJ. Diabetes and insulin resistance in older people. Med Clin North Am. 2011;95(3):615-29.

2. Corriere M, Rooparinesingh N, Kalyani RR. Epidemiology of diabetes and diabetes complications in the elderly: an emerging public health burden. Curr Diab Rep. 2013;13(6):805-13.

3. Sloan FA, Bethel MA, Ruiz D Jr., Shea AM, Feinglos MN. The growing burden of diabetes mellitus in the US elderly population. Arch Intern Med. 2008;168(2):192-9.

4. Roth GA, Forouzanfar MH, Moran AE, Barber R, Nguyen G, Feigin VL, et al. Demographic and epidemiologic drivers of global cardiovascular mortality. N Engl | Med. 2015;372(14):1333-41.

5. Sinclair A, Dunning T, Rodriguez-Manas L. Diabetes in older people: new insights and remaining challenges. Lancet Diabetes Endocrinol. 2015;3(4):275-85.

6. Johannsen DL, Conley KE, Bajpeyi S, Punyanitya M, Gallagher D, Zhang Z, et al. Ectopic lipid accumulation and reduced glucose tolerance in elderly adults are accompanied by altered skeletal muscle mitochondrial activity. J Clin Endocrinol Metab. 2012;97(1):242-50

7. Cnop M, Igoillo-Esteve M, Hughes S|, Walker JN, Cnop I, Clark A. Longevity of human islet alpha- and beta-cells. Diabetes Obes Metab. 2011;13(Suppl 1):39-46.

8. Gong Z, Muzumdar RH. Pancreatic function, type 2 diabetes, and metabolism in aging. Int J Endocrinol. 2012;2012:320482.

9. Meneilly GS, Ryan AS, Veldhuis JD, Elahi D. Increased disorderliness of basal insulin release, attenuated insulin secretory burst mass, and reduced ultradian rhythmicity of insulin secretion in older individuals. I Clin Endocrinol Metab. 1997;82(12):4088-93.

10. Amati F, Dube JJ, Coen PM, Stefanovic-Racic M, Toledo FG, Goodpaster $\mathrm{BH}$. Physical inactivity and obesity underlie the insulin resistance of aging. Diabetes Care. 2009;32(8):1547-9.

11. Bryhni $B$, lenssen $T G$, Olafsen $K$, Eikrem $H$. Age or waist as determinant of insulin action? Metabolism. 2003;52(7):850-7. 
12. DeFronzo RA, Hompesch M, Kasichayanula S, Liu X, Hong Y, Pfister M, et al. Characterization of renal glucose reabsorption in response to dapagliflozin in healthy subjects and subjects with type 2 diabetes. Diabetes Care. 2013;36(10):3169-76

13. DeFronzo RA, Davidson JA, Del Prato $S$. The role of the kidneys in glucose homeostasis: a new path towards normalizing glycaemia. Diabetes Obes Metab. 2012;14(1):5-14.

14. Merovci A, Solis-Herrera C, Daniele G, Eldor R, Fiorentino TV, Tripathy $D$, et al. Dapagliflozin improves muscle insulin sensitivity but enhances endogenous glucose production. J Clin Invest. 2014;124(2):509-14.

15. Cefalu WT, Leiter LA, Bruin TW, Gause-Nilsson I, Sugg J, Parikh SJ. Dapagliflozin's effects on glycemia and cardiovascular risk factors in high-risk patients with type 2 diabetes: a 24-week, multicenter, randomized, double-blind, placebo-controlled study with a 28-week extension. Diabetes Care. 2015;38(7):1218-27.

16. Ferrannini E, Muscelli E, Frascerra S, Baldi S, Mari A, Heise T, et al. Metabolic response to sodium-glucose cotransporter 2 inhibition in type 2 diabetic patients. J Clin Invest. 2014;124(2):499-508.

17. Bode B, Stenlof $K$, Harris S, Sullivan D, Fung A, Usiskin K, et al. Long-term efficacy and safety of canagliflozin over 104 weeks in patients aged 55-80 years with type 2 diabetes. Diabetes Obes Metab. 2015;17(3):294-303.

18. Zinman B, Wanner C, Lachin JM, Fitchett D, Bluhmki E, Hantel S, et al. Empagliflozin, cardiovascular outcomes, and mortality in type 2 diabetes. N Engl J Med. 2015;373(22):2117-28.

19. Tikkanen I, Narko K, Zeller C, Green A, Salsali A, Broedl UC, et al. Empagliflozin reduces blood pressure in patients with type 2 diabetes and hypertension. Diabetes Care. 2015;38(3):420-8.

20. Barnett AH, Mithal A, Manassie J, Jones R, Rattunde H, Woerle HJ, et al. Efficacy and safety of empagliflozin added to existing antidiabetes treatment in patients with type 2 diabetes and chronic kidney disease: a randomised, double-blind, placebo-controlled trial. Lancet Diabetes Endocrinol. 2014;2(5):369-84.

21. Bolinder J, Ljunggren $O$, Johansson L, Wilding J, Langkilde AM, Sjöström $C D$, et al. Dapagliflozin maintains glycaemic control while reducing weight and body fat mass over 2 years in patients with type 2 diabetes mellitus inadequately controlled on metformin. Diabetes Obes Metab. 2014;16(2):159-69.

22. Matthaei S, Bowering K, Rohwedder K, Sugg J, Parikh S, Johnsson E; et al. Durability and tolerability of dapagliflozin over 52 weeks as add-on to metformin and sulphonylurea in type 2 diabetes. Diabetes Obes Metab. 2015;17(11):1075-84.

23. Kohan DE, Fioretto P, Tang W, List JF. Long-term study of patients with type 2 diabetes and moderate renal impairment shows that dapagliflozin reduces weight and blood pressure but does not improve glycemic control. Kidney Int. 2014;85(4):962-71.

24. Leiter LA, Cefalu WT, Bruin TW, Gause-Nilsson I, Sugg |, Parikh SI. Dapagliflozin added to usual care in individuals with type 2 diabetes mellitus with preexisting cardiovascular disease: a 24-week, multicenter, randomized, double-blind, placebo-controlled study with a 28-week extension. Am Geriatr Soc. 2014;62(7):1252-62.

25. Neal B, Perkovic V, Zeeuw D, Mahaffey KW, Fulcher G, Ways K, et al. Efficacy and safety of canagliflozin, an inhibitor of sodium-glucose cotransporter 2, when used in conjunction with insulin therapy in patients with type 2 diabetes. Diabetes Care. 2015;38(3):403-11.

26. Yale JF, Bakris G, Cariou B, Nieto J, David-Neto E, Yue D, et al. Efficacy and safety of canagliflozin over 52 weeks in patients with type 2 diabetes mellitus and chronic kidney disease. Diabetes Obes Metab. 2014;16(10):101627.

27. Sinclair A, Bode B, Harris S, Vijapurkar U, Mayer C, Fung A, et al. Efficacy and safety of canagliflozin compared with placebo in older patients with type 2 diabetes mellitus: a pooled analysis of clinical studies. BMC Endocr Disord. 2014;14:37.

28. Bode B, Stenlof K, Sullivan D, Fung A, Usiskin K. Efficacy and safety of canagliflozin treatment in older subjects with type 2 diabetes mellitus: a randomized trial. Hosp Pract. 2013;41(2):72-84.

29. Moher D, Liberati A, Tetzlaff J, Altman DG, PRISMA Group. Preferred reporting items for systematic reviews and meta-analyses: the PRISMA statement. PLoS Med. 2009;6(7):e1000097.

30. Du YF, Ou HY, Beverly EA, Chiu C). Achieving glycemic control in elderly patients with type 2 diabetes: a critical comparison of current options. Clin Interv Aging. 2014;9:1963-80

31. Munshi MN, Segal AR, Suhl E, Staum E, Desrochers L, Sternthal A, et al.
Frequent hypoglycemia among elderly patients with poor glycemic control. Arch Intern Med. 2011;171(4):362-4.

32. Farahani P. Non-severe hypoglycemia risk difference between sulfonylurea and sodium-glucose cotransporter-2 inhibitors (SGLT2-I) as an add-on to metformin in randomized controlled trials. J Popul Ther Clin Pharmacol. 2017;24(2):e32-e40.

33. Treves C, Favilli F, Stio M, lantomasi T, Vincenzini MT. Changes in metabolite transport by small intestine and kidney of young and old rats. Mech Ageing Dev. 1990;52(2-3):263-76.

34. Laffin LJ, Bakris GL. Update on blood pressure goals in diabetes mellitus. Curr Cardiol Rep. 2015;17(6):37.

35. Maliha G, Townsend RR. SGLT2 inhibitors: their potential reduction in blood pressure. J Am Soc Hypertens. 2015;9(1):48-53.

36. Wright IT |r., Fine LI, Lackland DT, Ogedegbe G, Dennison Himmelfarb CR. Evidence supporting a systolic blood pressure goal of less than 150 $\mathrm{mm} \mathrm{Hg}$ in patients aged 60 years or older: the minority view. Ann Intern Med. 2014;160(7):499-503.

37. Aronow WS, Fleg |L, Pepine Cl, Artinian NT, Bakris G, Brown AS, et al. ACCF/AHA 2011 expert consensus document on hypertension in the elderly: a report of the American College of Cardiology Foundation Task Force on Clinical Expert Consensus documents developed in collaboration with the American Academy of Neurology, American Geriatrics Society, American Society for Preventive Cardiology, American Society of Hypertension, American Society of Nephrology, Association of Black Cardiologists, and European Society of Hypertension. J Am Coll Cardiol. 2011;57(20):2037-114

38. Palombo C, Kozakova M. Arterial stiffness, atherosclerosis and cardiovascular risk: pathophysiologic mechanisms and emerging clinical indications. Vascul Pharmacol. 2016;77:1-7.

39. Xue M, Rabbani N, Thornalley PJ. Glyoxalase in ageing. Semin Cell Dev Biol. 2011;22(3):293-301.

40. Choi KM, Yoo HJ, Kim HY, Lee KW, Seo JA, Kim SG, et al. Association between endogenous secretory RAGE, inflammatory markers and arterial stiffness. Int | Cardiol. 2009;132(1):96-101.

41. Elewa U, Fernandez-Fernandez $B$, Alegre R, Sanchez-Niño MD, Mahillo-Fernández I Perez-Gomez MV, et al. Modifiable risk factors for increased arterial stiffness in outpatient nephrology. PLoS One. 2015;10(4):e0123903.

42. Chilton R, Tikkanen I, Cannon CP, Crowe S, Woerle HI, Broedl UC, et al. Effects of empagliflozin on blood pressure and markers of arterial stiffness and vascular resistance in patients with type 2 diabetes. Diabetes Obes Metab. 2015;17(12):1180-93.

43. Cherney DZ, Perkins BA, Soleymanlou N, Har R, Fagan N, Johansen OE, et al. The effect of empagliflozin on arterial stiffness and heart rate variability in subjects with uncomplicated type 1 diabetes mellitus. Cardiovasc Diabetol. 2014;13:28.

44. Oelze M, Kroller-Schon S, Welschof P, Jansen T, Hausding M, Mikhed Y, et al. The sodium-glucose co-transporter 2 inhibitor empagliflozin improves diabetes-induced vascular dysfunction in the streptozotocin diabetes rat model by interfering with oxidative stress and glucotoxicity. PloS One. 2014;9(11):e112394.

45. Fulcher G, Matthews DR, Perkovic V, Zeeuw D, Mahaffey KW, Mathieu C, et al. Efficacy and safety of canagliflozin when used in conjunction with incretin-mimetic therapy in patients with type 2 diabetes. Diabetes Obes Metab. 2016;18(1):82-91.

46. Lambers Heerspink HI, Zeeuw D, Wie L, Leslie B, List I. Dapagliflozin a glucose-regulating drug with diuretic properties in subjects with type 2 diabetes. Diabetes Obes Metab. 2013;15(9):853-62.

47. Basile J. Hypertension in the elderly: a review of the importance of systolic blood pressure elevation. | Clin Hypertens (Greenwich). 2002;4(2):108-12.

48. Weber MA, Mansfield TA, Cain VA, lqbal N, Parikh S, Ptaszynska A. Blood pressure and glycaemic effects of dapagliflozin versus placebo in patients with type 2 diabetes on combination antihypertensive therapy: a randomised, double-blind, placebo-controlled, phase 3 study. Lancet Diabetes Endocrinol. 2016;4(3):211-20.

49. Sha S, Polidori D, Heise T, Natarajan I, Farrell K, Wang SS, et al. Effect of the sodium glucose co-transporter 2 inhibitor canagliflozin on plasma volume in patients with type 2 diabetes mellitus. Diabetes Obes Metab. 2014;16(11):1087-95

50. Siebenhofer A, Jeitler K, Berghold A, Waltering A, Hemkens LG, Semlitsch $T$, et al. Long-term effects of weight-reducing diets in hypertensive patients. Cochrane Database Syst Rev. 2011:(9):CD008274. 
51. Sjostrom CD, Hashemi M, Sugg J, Ptaszynska A, Johnsson E. Dapagliflozin-induced weight loss affects 24-week glycated haemoglobin and blood pressure levels. Diabetes Obes Metab. 2015;17(8):809-12.

52. Iqbal J, Denvir M, Gunn J. Frailty assessment in elderly people. Lancet. 2013;381(9882):1985-6.

53. Fabbri E, Tanaka T, An Y, Zoli M, Bandinelli S, Guralnik IM, et al. Loss of weight in obese older adults: a biomarker of impending expansion of multimorbidity? J Am Geriatr Soc. 2015;63(9):1791-7.

54. Newman AB, Yanez D, Harris T, Duxbury A, Enright PL, Fried LP, et al. Weight change in old age and its association with mortality. J Am Geriatr Soc. 2001;49(10):1309-18.

55. Shea MK, Nicklas BJ, Houston DK, Miller ME, Davis CC, Kitzman DW, et al. The effect of intentional weight loss on all-cause mortality in older adults: results of a randomized controlled weight-loss trial. Am J Clin Nutr. 2011;94(3):839-46

56. Wijnhoven HA, van Zon SK, Twisk J, Visser M. Attribution of causes of weight loss and weight gain to 3-year mortality in older adults: results from the Longitudinal Aging Study Amsterdam. J Gerontol A Biol Sci Med Sci. 2014;69(10):1236-43.

57. Katzel LI, Bleecker ER, Colman EG, Rogus EM, Sorkin ID, Goldberg AP. Effects of weight loss vs aerobic exercise training on risk factors for coronary disease in healthy, obese, middle-aged and older men. A randomized controlled trial. JAMA. 1995;274(24):1915-21.

58. Purnell JQ, Kahn SE, Albers JJ, Nevin DN, Brunzell JD, Schwartz RS. Effect of weight loss with reduction of intra-abdominal fat on lipid metabolism in older men. J Clin Endocrinol Metab. 2000;85(3):977-82.

59. Dengel DR, Pratley RE, Hagberg JM, Rogus EM, Goldberg AP. Distinct effects of aerobic exercise training and weight loss on glucose homeostasis in obese sedentary men. J Appl Physiol. 1996;81(1):318-25.

60. Beavers KM, Miller ME, Rejeski WJ, Nicklas BJ, Kritchevsky SB. Fat mass loss predicts gain in physical function with intentional weight loss in older adults. J Gerontol A Biol Sci Med Sci. 2013;68(1):80-6.

61. Sipila S, Koskinen SO, Taaffe DR, Takala TE, Cheng S, Rantanen T, et al. Determinants of lower-body muscle power in early postmenopausal women. J Am Geriatr Soc. 2004;52(6):939-44.

62. Sipila $\mathrm{S}$, Suominen $\mathrm{H}$. Knee extension strength and walking speed in relation to quadriceps muscle composition and training in elderly women. Clin Physiol. 1994;14(4):433-42.

63. Goodpaster BH, Carlson CL, Visser M, Kelley DE, Scherzinger A, Harris $T B$, et al. Attenuation of skeletal muscle and strength in the elderly: the Health ABC Study. J Appl Physiol. 2001;90(6):2157-65.

64. Visser M, Kritchevsky SB, Goodpaster BH, Newman AB, Nevitt M, Stamm $E$, et al. Leg muscle mass and composition in relation to lower extremity performance in men and women aged 70 to 79 : the health, aging and body composition study. I Am Geriatr Soc. 2002;50(5):897-904.

65. Newman AB, Kupelian V, Visser M, Simonsick EM, Goodpaster BH, Kritchevsky SB, et al. Strength, but not muscle mass, is associated with mortality in the health, aging and body composition study cohort. Gerontol A Biol Sci Med Sci. 2006;61(1):72-7.

66. Visser M, Goodpaster BH, Kritchevsky SB, Newman AB, Nevitt M, Rubin $\mathrm{SM}$, et al. Muscle mass, muscle strength, and muscle fat infiltration as predictors of incident mobility limitations in well-functioning older persons. Gerontol A Biol Sci Med Sci. 2005;60(3):324-33.

67. Aguirre L, Napoli N, Waters D, Qualls C, Villareal DT, Armamento-Villareal R. Increasing adiposity is associated with higher adipokine levels and lower bone mineral density in obese older adults. J Clin Endocrinol Metab. 2014;99(9):3290-7.

68. Jahangir E, De Schutter A, Lavie CJ. Low weight and overweightness in older adults: risk and clinical management. Prog Cardiovasc Dis. 2014;57(2):127-33.

69. Matthaei S, Bowering K, Rohwedder K, Grohl A, Parikh S, Study 05 Group. Dapagliflozin improves glycemic control and reduces body weight as addon therapy to metformin plus sulfonylurea: a 24-week randomized, double-blind clinical trial. Diabetes Care. 2015;38(3):365-72.

70. Fulcher G, Matthews DR, Perkovic V, Zeeuw D, Mahaffey KW, Weiss R, et al. Efficacy and safety of canagliflozin used in conjunction with sulfonylurea in patients with type 2 diabetes mellitus: a randomized, controlled trial. Diabetes Ther. 2015;6(3):289-302.

71. Ferrannini G, Hach T, Crowe S, Sanghvi A, Hall KD, Ferrannini E. Energy balance after sodium-glucose cotransporter 2 inhibition. Diabetes Care. 2015;38(9):1730-5

72. Chiba Y, Yamada T, Tsukita S, Takahashi K, Munakata Y, Shirai Y, et al.
Dapagliflozin, a sodium-glucose co-transporter 2 inhibitor, acutely reduces energy expenditure in BAT via neural signals in mice. PloS One. 2016;11(3):e0150756.

73. Del Prato S, Nauck M, Duran-Garcia S, Maffei L, Rohwedder K, Theuerkauf $A$, et al. Long-term glycaemic response and tolerability of dapagliflozin versus a sulphonylurea as add-on therapy to metformin in patients with type 2 diabetes: 4-year data. Diabetes Obes Metab. 2015;17:581-90.

74. Lee CG, Boyko EJ, Barrett-Connor E, Miljkovic I, Hoffman AR, Everson-Rose SA, et al. Insulin sensitizers may attenuate lean mass loss in older men with diabetes. Diabetes Care. 2011;34(11):2381-6.

75. Levey AS, Inker LA, Coresh J. Chronic kidney disease in older people. JAMA. 2015;314(6):557-8.

76. Hallan SI, Dahl K, Oien CM, Grootendorst DC, Aasberg A, Holmen J, et al. Screening strategies for chronic kidney disease in the general population: follow-up of cross sectional health survey. BM). 2006;333(7577):1047.

77. Tuttle KR, Bakris GL, Bilous RW, Chiang |L, Boer IH, Goldstein-Fuchs |, et al. Diabetic kidney disease: a report from an ADA Consensus Conference. Am J Kidney Dis. 2014;64(4):510-33.

78. Hallan SI, Matsushita K, Sang Y, Mahmoodi BK, Black C, Ishani A, et al. Age and association of kidney measures with mortality and end-stage renal disease. JAMA. 2012;308(22):2349-60.

79. Denic A, Glassock RJ, Rule AD. Structural and functional changes with the aging kidney. Adv Chronic Kidney Dis. 2016;23(1):19-28.

80. Blazer S, Khankin E, Segev Y, Ofir R, Yalon-Hacohen M, Kra-Oz Z, et al. High glucose-induced replicative senescence: point of no return and effect of telomerase. Biochem Biophys Res Commun. 2002;296(1):93-101.

81. Yokoi T, Fukuo K, Yasuda O, Hotta M, Miyazaki J, Takemura Y, et al. Apoptosis signal-regulating kinase 1 mediates cellular senescence induced by high glucose in endothelial cells. Diabetes. 2006;55(6):1660-5.

82. Verzola D, Gandolfo MT, Gaetani G, Ferraris A, Mangerini R, Ferrario F, et al. Accelerated senescence in the kidneys of patients with type 2 diabetic nephropathy. Am | Physiol Renal Physiol. 2008;295(5):F1563-73.

83. Kitada K, Nakano D, Ohsaki H, Hitomi H, Minamino T, Yatabe J, et al. Hyperglycemia causes cellular senescence via a SGLT2- and p21-dependent pathway in proximal tubules in the early stage of diabetic nephropathy. I Diabetes Complications. 2014;28(5):604-11.

84. De Nicola L, Gabbai FB, Liberti ME, Sagliocca A, Conte G, Minutolo R. Sodium/glucose cotransporter 2 inhibitors and prevention of diabetic nephropathy: targeting the renal tubule in diabetes. Am J Kidney Dis. 2014; 64:16-24.

85. Gallagher H, Suckling RJ. Diabetic nephropathy: where are we on the journey from pathophysiology to treatment? Diabetes Obes Metab. 2016;18(7):641-7.

86. Freitas HS, Anhe GF, Melo KF, Okamoto MM, Oliveira-Souza M, Bordin S, et al. $\mathrm{Na}(+)$-glucose transporter-2 messenger ribonucleic acid expression in kidney of diabetic rats correlates with glycemic levels: involvement of hepatocyte nuclear factor-1alpha expression and activity. Endocrinology. 2008;149(2):717-24

87. Rahmoune H, Thompson PW, Ward JM, Smith CD, Hong G, Brown J. Glucose transporters in human renal proximal tubular cells isolated from the urine of patients with non-insulin-dependent diabetes. Diabetes. 2005;54(12):3427-34.

88. Cherney DZ, Perkins BA, Soleymanlou N, Maione M, Lai V, Lee A, et al. Renal hemodynamic effect of sodium-glucose cotransporter 2 inhibition in patients with type 1 diabetes mellitus. Circulation. 2014;129(5):587-97.

89. Skrtic M, Cherney DZ. Sodium-glucose cotransporter-2 inhibition and the potential for renal protection in diabetic nephropathy. Curr Opin Nephrol Hypertens. 2015;24(1):96-103.

90. Nakamura N, Masuda S, Takahashi K, Saito H, Okuda M, Inui K. Decreased expression of glucose and peptide transporters in rat remnant kidney. Drug Metab Pharmacokinet. 2004;19(1):41-7.

91. Ghezzi C, Hirayama BA, Gorraitz E, Loo DD, Liang Y, Wright EM. SGLT2 inhibitors act from the extracellular surface of the cell membrane. Physiol Rep. 2014;2(6)

92. Sha S, Polidori D, Farrell K, Ghosh A, Natarajan J, Vaccaro N, et al. Pharmacodynamic differences between canagliflozin and dapagliflozin: results of a randomized, double-blind, crossover study. Diabetes Obes Metab. 2015;17(2):188-97.

93. Townsend RR, Taler SJ. Management of hypertension in chronic kidney disease. Nat Rev Nephrol. 2015;11(9):555-63.

94. Palmer SC, Mavridis D, Navarese E, Craig JC, Tonelli M, Salanti G, et al. Comparative efficacy and safety of blood pressure-lowering agents in 
adults with diabetes and kidney disease: a network meta-analysis. Lancet. 2015;385(9982):2047-56.

95. Navaneethan SD, Yehnert H, Moustarah F, Schreiber MJ, Schauer PR, Beddhu S. Weight loss interventions in chronic kidney disease: a systematic review and meta-analysis. Clin J Am Soc Nephrol. 2009;4(10):1565-74.

96. Perkovic V, Jardine M, Vijapurkar U, Meininger G. Renal effects of canagliflozin in type 2 diabetes mellitus. Curr Med Res Opin. 2015;31(12):2219-31.

97. Cherney DZ, Perkins BA, Soleymanlou N, Xiao F, Zimpelmann |, Woerle $\mathrm{HJ}$, et al. Sodium glucose cotransport-2 inhibition and intrarenal RAS activity in people with type 1 diabetes. Kidney Int. 2014;86(5):1057-8.

98. Kohan DE, Fioretto P, Johnsson K, Parikh S, Ptaszynska A, Ying L. The effect of dapagliflozin on renal function in patients with type 2 diabetes. Nephrol. 2016;29(3):391-400

99. Yale JF, Bakris G, Cariou B, Yue D, David-Neto E, Xi L, et al. Efficacy and safety of canagliflozin in subjects with type 2 diabetes and chronic kidney disease. Diabetes Obes Metab. 2013;15(5):463-73.

100. Wilding JP, Norwood P, T'Joen C, Bastien A, List JF, Fiedorek FT. A study of dapagliflozin in patients with type 2 diabetes receiving high doses of insulin plus insulin sensitizers: applicability of a novel insulin-independent treatment. Diabetes Care. 2009;32(9):1656-62.

101. List JF, Woo V, Morales E, Tang W, Fiedorek FT. Sodium-glucose cotransport inhibition with dapagliflozin in type 2 diabetes. Diabetes Care. 2009;32(4):650-7.

102. Hayashi T, Takai S, Yamashita C. Impact of the renin-angiotensin-aldosterone-system on cardiovascular and renal complications in diabetes mellitus. Curr Vasc Pharmacol. 2010;8(2):189-97.

103. Yamout H, Perkovic V, Davies M, Woo V, Zeeuw D, Mayer C, et al. Efficacy and safety of canagliflozin in patients with type 2 diabetes and stage 3 nephropathy. Am J Nephrol. 2014;40(1):64-74.

104.Devineni D, Vaccaro N, Polidori D, Rusch S, Wajs E. Effects of hydrochlorothiazide on the pharmacokinetics, pharmacodynamics, and tolerability of canagliflozin, a sodium glucose co-transporter 2 inhibitor, in healthy participants. Clin Ther. 2014;36(5):698-710.

105. Erondu N, Desai M, Ways K, Meininger G. Diabetic ketoacidosis and related events in the canagliflozin type 2 diabetes clinical program. Diabetes Care. 2015;38(9):1680-6.

106. Kaku K, Watada H, Iwamoto $Y$, Utsunomiya K, Terauchi $Y$, Tobe K, et al. Efficacy and safety of monotherapy with the novel sodium/glucose cotransporter-2 inhibitor tofogliflozin in lapanese patients with type 2 diabetes mellitus: a combined Phase 2 and 3 randomized, placebo-controlled, double-blind, parallel-group comparative study. Cardiovasc Diabetol. 2014:13:65.

107. Bonner C, Kerr-Conte J, Gmyr V, Queniat G, Moerman E, Thévenet J, et al. Inhibition of the glucose transporter SGLT2 with dapagliflozin in pareatic alpha cells triggers glucagon secretion. Nat Med. 2015;21(5):512-7.

108. Taylor SI, Blau JE, Rother KI. Perspective: SGLT2 inhibitors may predispose to ketoacidosis. J Clin Endocrinol Metab. 2015;100(8):2849-52.

109. Rosenstock |, Ferrannini E. Euglycemic diabetic ketoacidosis: a predictable, detectable, and preventable safety concern with SGLT2 inhibitors. Diabetes Care 2015;38(9):1638-42.

110. Tuomi T, Santoro N, Caprio S, Cai M, Weng J, Groop L. The many faces of diabetes: a disease with increasing heterogeneity. Lancet. 2014;383(9922):1084-94

111. Itariu BK, Stulnig TM. Autoimmune aspects of type 2 diabetes mellitus: a mini-review. Gerontology. 2014;60(3):189-96.

112. Duckworth W, Abraira C, Moritz T, Reda D, Emanuele N, Reaven PD, et al. Glucose control and vascular complications in veterans with type 2 diabetes. N Engl I Med. 2009;360(2):129-39.

113. Signorovitch JE, Macaulay D, Diener M, Yan Y, Wu EQ, Gruenberger JB, et al. Hypoglycaemia and accident risk in people with type 2 diabetes mellitus treated with non-insulin antidiabetes drugs. Diabetes Obes Metab. 2013;15(4):335-41.

114. Johnston SS, Conner C, Aagren M, Ruiz K, Bouchard J. Association between hypoglycaemic events and fall-related fractures in Medicare-covered patients with type 2 diabetes. Diabetes Obes Metab. 2012;14(7):634-43.

115. Feinkohl I, Aung PP, Keller M, Robertson CM, Morling JR, McLachlan $\mathrm{S}$, et al. Severe hypoglycemia and cognitive decline in older people with type 2 diabetes: the Edinburgh type 2 diabetes study. Diabetes Care. 2014;37(2):507-15

116. Mattishent $\mathrm{K}$, Loke YK. Bi-directional interaction between hypoglycaemia and cognitive impairment in elderly patients treated with glucose lower- ing agents: systematic review and meta-analysis. Diabetes Obes Metab. 2016;18(2):135-41

117. Lipska KJ, Montori VM. Glucose control in older adults with diabetes mellitus: more harm than good? JAMA Intern Med. 2013;173(14):1306-7.

118. Hirji I, Guo Z, Andersson SW, Hammar N, Gomez-Caminero A. Incidence of urinary tract infection among patients with type 2 diabetes in the UK General Practice Research Database (GPRD). J Diabetes Complications. 2012;26(6):513-6.

119. Geerlings S, Fonseca V, Castro-Diaz D, List J, Parikh S. Genital and urinary tract infections in diabetes: impact of pharmacologically-induced glucosuria. Diabetes Res Clin Pract. 2014;103(3):373-81.

120. Johnsson KM, Ptaszynska A, Schmitz B, Sugg J, Parikh SI, List JF. Vulvovaginitis and balanitis in patients with diabetes treated with dapagliflozin. | Diabetes Complications. 2013;27(5):479-84.

121. Liakos A, Karagiannis T, Athanasiadou E, Sarigianni M, Mainou M, Papatheodorou $\mathrm{K}$, et al. Efficacy and safety of empagliflozin for type 2 diabetes: a systematic review and meta-analysis. Diabetes Obes Metab. 2014;16(10):984-93.

122. Nyirjesy P, Sobel JD, Fung A, Mayer C, Capuano G, Ways K, et al. Genital mycotic infections with canagliflozin, a sodium glucose co-transporter 2 inhibitor, in patients with type 2 diabetes mellitus: a pooled analysis of clinical studies. Curr Med Res Opin. 2014;30(6):1109-19.

123. Jackuliak P, Payer J. Osteoporosis, fractures, and diabetes. Int J Endocrinol. 2014;2014:820615.

124. Strotmeyer ES, Cauley JA, Schwartz AV, Nevitt MC, Resnick HE, Bauer DC, et al. Nontraumatic fracture risk with diabetes mellitus and impaired fasting glucose in older white and black adults: the health, aging, and body composition study. Arch Intern Med. 2005;165(14):1612-7.

125. Thrailkill KM, Clay Bunn R, Nyman JS, Rettiganti MR, Cockrell GE, Wahl EC, et al. SGLT2 inhibitor therapy improves blood glucose but does not prevent diabetic bone disease in diabetic DBA/2] male mice. Bone 2016;82:101-7.

126. Ljunggren O, Bolinder J, Johansson L, Wilding J, Langkilde AM, Sjöström $C D$, et al. Dapagliflozin has no effect on markers of bone formation and resorption or bone mineral density in patients with inadequately controlled type 2 diabetes mellitus on metformin. Diabetes Obes Metab. 2012;14(11):990-9.

127. Bilezikian JP, Watts NB, Usiskin K, Polidori D, Fung A, Sullivan D, et al. Evaluation of bone mineral density and bone biomarkers in patients with type 2 diabetes treated with canagliflozin. J Clin Endocrinol Metab. 2016;101(1):44-51.

128. Alba M, Xie J, Fung A, Desai M. The effects of canagliflozin, a sodium glucose co-transporter 2 inhibitor, on mineral metabolism and bone in patients with type 2 diabetes mellitus. Curr Med Res Opin. 2016;32(8):137585.

129. Palermo A, D'Onofrio L, Eastell R, Schwartz AV, Pozzilli P, Napoli N. Oral anti-diabetic drugs and fracture risk, cut to the bone: safe or dangerous? A narrative review. Osteoporos Int. 2015;26(8):2073-89.

130. Vestergaard $P$. Discrepancies in bone mineral density and fracture risk in patients with type 1 and type 2 diabetes: a meta-analysis. Osteoporos Int. 2007;18(4):427-44.

131. Watts NB, Bilezikian JP, Usiskin K, Edwards R, Desai M, Law G, et al. Effects of canagliflozin on fracture risk in patients with type 2 diabetes mellitus. | Clin Endocrinol Metab. 2016;101(1):157-66.

132. Wu JH, Foote C, Blomster I, Toyama T, Perkovic V, Sundström I, et al. Effects of sodium-glucose cotransporter-2 inhibitors on cardiovascular events, death, and major safety outcomes in adults with type 2 diabetes: a systematic review and meta-analysis. Lancet Diabetes Endocrinol. 2016;4(5):411-9

133. Cholesterol Treatment Trialists' (CTT) Collaborators, Kearney PM, Blackwell L, Collins R, Keech A, Simes J, Peto R, et al. Efficacy of cholesterol-lowering therapy in 18,686 people with diabetes in 14 randomised trials of statins: a meta-analysis. Lancet. 2008;371(9607):117-25.

134. Brandenburg VM, Kleber ME, Vervloet MG, Tomaschitz A, Pilz S, Stojakovic T, et al. Fibroblast growth factor 23 (FGF23) and mortality: the Ludwigshafen Risk and Cardiovascular Health Study. Atherosclerosis. 2014;237(1):53-9

135. Yin J, Lu Z, Wang F, Jiang Z, Lu L, Miao N, et al. Renalase attenuates hypertension, renal injury and cardiac remodelling in rats with subtotal nephrectomy. J Cell Mol Med. 2016;20(6):1106-17.

136. Anzawa R, Bernard M, Tamareille S, Baetz D, Confort-Gouny S, Gascard IP, et al. Intracellular sodium increase and susceptibility to 
ischaemia in hearts from type 2 diabetic $\mathrm{db} / \mathrm{db}$ mice. Diabetologia. 2006;49(3):598-606.

137. Tung P, Albert CM. Causes and prevention of sudden cardiac death in the elderly. Nat Rev Cardiol. 2013;10(3):135-42.

138. El-Menyar AA. Dysrhythmia and electrocardiographic changes in diabetes mellitus: pathophysiology and impact on the incidence of sudden cardiac death. J Cardiovasc Med. 2006;7(8):580-5.

139. Banerjee SK, McGaffin KR, Pastor-Soler NM, Ahmad F. SGLT1 is a novel cardiac glucose transporter that is perturbed in disease states. Cardiovasc Res 2009;84(1):111-8.

140. Scheen AJ. Pharmacokinetic and pharmacodynamic profile of empagliflozin, a sodium glucose co-transporter 2 inhibitor. Clin Pharmacokinet. 2014;53(3):213-25.

141. Mudaliar S, Alloju S, Henry RR. Can a shift in fuel energetics explain the beneficial cardiorenal outcomes in the EMPA-REG OUTCOME study? A unifying hypothesis. Diabetes Care. 2016;39(7):1115-22.

142. Kupari M, Lommi J, Ventila M, Karjalainen U. Breath acetone in congestive heart failure. Am J Cardiol. 1995;76(14):1076-8.

143. Ashrafian H, Frenneaux MP, Opie LH. Metabolic mechanisms in heart failure. Circulation. 2007;116(4):434-48.

144. effrey FM, Diczku V, Sherry AD, Malloy CR. Substrate selection in the isolated working rat heart: effects of reperfusion, afterload, and concen- tration. Basic Res Cardiol. 1995;90(5):388-96.

145. Freemantle E, Vandal M, Tremblay Mercier J, Plourde M, Poirier J, Cunnane SC. Metabolic response to a ketogenic breakfast in the healthy elderly. J Nutr Health Aging. 2009;13(4):293-8.

146. Kernan WN, Viscoli CM, Furie KL, Young LH, Inzucchi SE, Gorman M, et al. Pioglitazone after ischemic stroke or transient ischemic attack. N Engl | Med. 2016;374(14):1321-31.

147. Emdin CA, Rahimi K, Neal B, Callender T, Perkovic V, Patel A. Blood pressure lowering in type 2 diabetes: a systematic review and meta-analysis. |AMA 2015;313(6):603-15.

148. Ricci F, Fedorowski A, Radico F, Romanello M, Tatasciore A, Di Nicola M, et al. Cardiovascular morbidity and mortality related to orthostatic hypotension: a meta-analysis of prospective observational studies. Eur Heart . 2015;36(25):1609-17.

149. Laragh JH, Sealey JE. Abnormal sodium metabolism and plasma renin activity (renal renin secretion) and the vasoconstriction volume hypothesis: implications for pathogenesis and treatment of hypertension and its vascular consequences (heart attack, stroke). Clin Chem. 1991;37(10 pt 2):1820-7.

150. Mollsten A, Stegmayr B, Wiklund PG. Genetic polymorphisms in the renin-angiotensin system confer increased risk of stroke independently of blood pressure: a nested case-control study. J Hypertens. 2008;26(7):1367-72 